\title{
Investigation into the use of thermoelectric modules as an alternative to conventional fluxmeters: application to convective and radiative heat flux in buildings
}

\author{
Miguel Chen Austin ${ }^{\mathrm{a}, \mathrm{b}}$, Tingting Vogt Wua, Alain Sempey, Alain Sommiera, Jean Dumouline, Denis \\ Bruneau $^{\mathrm{a}, \mathrm{d}}$, Jean-Christophe Batsale ${ }^{\mathrm{a}}$, Yingying Yang ${ }^{\mathrm{c}, *}$ \\ a Institute of Mechanical Engineering (I2M), UMR 5295, CNRS, and University of Bordeaux, Arts et Métiers ParisTech, \\ Bordeaux INP, INRA, France \\ ${ }^{\mathrm{b}}$ Universidad Tecnologica de Panama, Faculty of Mechanical Engineering, Avenida Domingo Diaz, Ciudad de Panama, \\ ${ }^{\mathrm{c}}$ School of Energy and Power Engineering, University of Shanghai for Science and Technology, 516 Jungong Road, Shanghai, \\ ${ }^{\mathrm{d}}$ GRECCAU, EA 7482, ENSAP Bordeaux, 33405, TALENCE, France \\ ${ }^{\mathrm{e}}$ University of Gustave Eiffel, Inria, COSYS-SII, I4S Team, Bouguenais, F-44344, France \\ * Corresponding author. E-mail addresses: yangyy741@126.com, yingyingyang@usst.edu.cn (Y. Yang).
} Panama 200093, China

\section{Abstract}

The present work aims to propose the use of Peltier modules for the superficial heat flux measurement, as an alternative to conventional heat flux sensors. In this study, the function of Peltier modules (TEM) as heat flux sensors is compared to the Captec ${ }^{\circledR}$ heat flux sensors (FGT), based on the premise that conventional heat flux sensors such as Captec ${ }^{\circledR}$ have been proven to have acceptable performance for the heat flux measurement, i.e., conduction, convection and radiation. A simple measurement device and a simple general formulation for decoupling the convective and radiative parts from the heat flux measurement are proposed. The latter are implemented in an experimental case presenting weak convective and radiative heat fluxes, using a black-shiny couple of Peltier modules and a black-shiny couple of Captec. The radiative part was found to be the same when comparing FGT and TEM measurements. However, the convective part when using TEM measurements was found to be around two times larger than when using FGT measurement. It has been encountered that this difference is better explained by the geometrical and thermal properties of both sensors.

Keywords: Heat flux measurement, thermoelectric modules, Peltier modules, heat flux sensor, convective heat flux, radiative heat flux. 
In various thermal engineering fields, the needs of predicting models gradually require a more precise estimation of the real value of the thermal stresses, e.g., superficial heat transfer, absorbed heat flux, to verify the reliability model-measurement when accounting for such thermal stresses. For instance, in the calculations of cooling or heating needs in order to maintain the internal thermal comfort in buildings; in the characterization of walls to determine the incoming and outgoing heat flux through the walls $[1,2]$; in the estimation of convective and radiative heat transfer in heat exchangers [3]; in the estimation of the convective heat transfer in ovens for drying [4]. In this context, thermal engineers had proposed more than 30 years ago a widely used technique for heat flux measurement able to estimate the heat flux through the surface (conduction), and at the surface (convection and radiation). This technique is based on the use of flat-plate heat flux sensors (also known as conventional or classical heat flux meters); sensors that are about ten times more expensive than a Peltier module of the same size. For example a conventional heat flux sensor of $4 \times 4 \mathrm{~cm}^{2}$ of type Captec ${ }^{\circledR}$ costs around $600 €$, whereas a Peltier module of this size costs around $20 €$. Thus, this has led researchers to think of an alternative way, proposing a technique based on the use of single-stage Peltier modules for the heat flux measurement. Another leading cause lays in that, although Peltier modules are not designed to measure heat flux, their use is very attractive because, when used for this purpose, they present stronger thermoelectric power compared to a Captec ${ }^{\circledR}$ of the same size and even one of a bigger size, which allows in principle to measure weak thermal loads more precisely.

However, Peltier modules response time (about one minute) limits their implementation to somewhat slow processes, due to the materials used for its fabrication. For example, in buildings, a significant change in the evolution of the envelope temperature can be detected in a couple of hours, which indicates that the thermal stresses also present significant variation on similar duration. In such a case, a heat flux sensor with a quick response time is not absolutely needed.

Moreover, although Peltier modules has not been employed as large as conventional heat flux sensors for the heat flux measurement, according to the reported literature, it has been found that the former works satisfactory well enough in the estimation of the Solar radiation heat flux [5]. Conversely, in the estimation of the convective heat flux, it has been found that Peltier modules overestimate its magnitude by about a factor of two [6,7]. Therefore, for all these reasons and based on the premise that conventional heat flux sensors such as Captec $®$ has been proven to perform well enough [3], it was found quite interesting to study and compared the use of Peltier modules with Captec, to conclusively propose a thorough methodology for implementing the former as an alternative to the latter, in the estimation of the superficial heat transfer (convection and radiation). 


\subsection{Background on the heat flux measurement with flat-plate sensors}

In this type of heat flux meters, the measurement is based on the Seebeck effect. The voltage difference $U$ at the sensor electrical terminals is proportional to the heat flux traversing the sensor $q$, both related by a thermoelectric coefficient $[1,3,8]$. This before can be represented by a simple equation, as follows:

$$
q=\frac{U}{K} \quad\left[\mathrm{~W} \cdot \mathrm{m}^{-2}\right]
$$

where $U$ is normally expressed in $\mu \mathrm{V}$ and $q$ is the measured heat flux or traversing the sensor. $U$ can take positive and negative values, depending on the heat flux direction and on the polarity connection of the sensor electrical terminals. The coefficient $K$ is the sensitivity value of the sensor, which groups its thermoelectric properties, e.g., the Seebeck coefficient $a_{e q}$, the total number of thermocouple junctions $N$, and the thermal conductivity $\lambda_{e q}$; normally expressed in $\mu \mathrm{V} / \mathrm{W} \cdot \mathrm{m}^{-2}$ and it is usually determined by calibration techniques. The relation between these magnitudes could be demonstrated to be equal to the following expression:

$$
K=\frac{N a_{e q} e}{\lambda_{e q}} \quad\left[\mu \mathrm{V} / \mathrm{W} \cdot \mathrm{m}^{-2}\right]
$$

where $e$ corresponds to the thickness of the active section of the sensor. Expression 2 results from replacing Fourier's conduction equation, and the thermoelectric relationship between voltage and temperature difference $(U=a \Delta T)$, into equation 1 .

Moreover, the value of the sensitivity $K$ might vary with the temperature of the thermoelectric junctions due to the thermoelectric properties of the materials used for this kind of sensors. This might rarely happen when the sensor is manufactured with metal alloys. However, when using semiconductors for the thermocouples junctions, $K$ may vary, since their Seebeck coefficient and thermal conductivity do vary with the average temperature of the junctions; although a significant variation might only be encountered when the temperature rises above some hundreds of degrees [9].

\subsubsection{Conventional heat flux sensor: Tangential temperature gradient}



thermopile, distributed all over the surface of an insulated support (based on the printed circuit board technique). This support is then covered by two plates of copper, on each side (see figure 1 (a)). When both plates of this embedded element are submitted to different temperatures, each of the thermocouple junctions generates a voltage difference due to the temperature gradient and the Seebeck effect principle (see figure 1 (b)). These sensors are also designed as to measure the temperature at a middle plane between both copper plates [3].

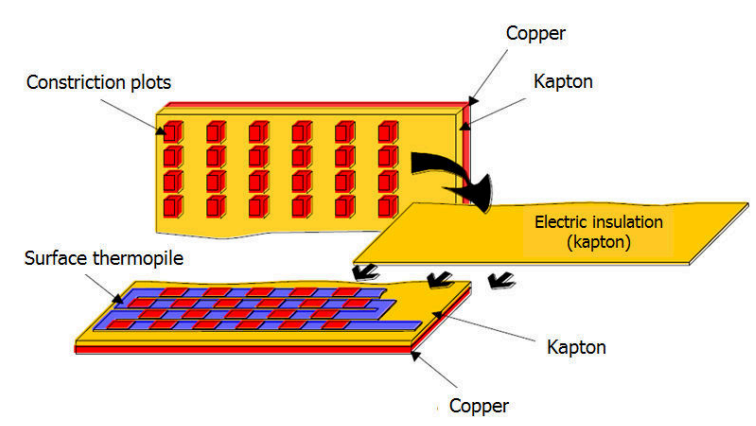

(a)

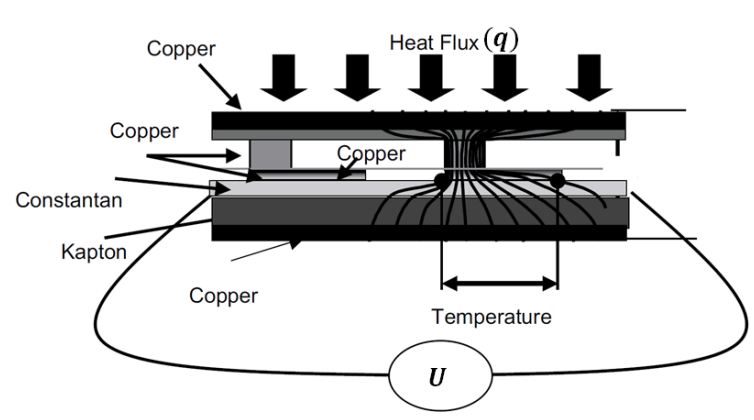

(b)

Figure 1. Structure of Captec $₫$ heat flux meter: (a) Composition, and (b) transversal side view with heat flux lines [3].

This type of conventional heat flux sensors are widely found in the market, for instance, Captec ${ }^{\circledR}$ enterprise, offers square heat flux meters with a dimension range between $5 \times 5 \mathrm{~mm}^{2}$ and $300 \times 300 \mathrm{~mm}^{2}$ with a thickness of about $0,5 \mathrm{~mm}$ or thinner. Depending on these dimensions, their sensibility value can vary from some $\mu \mathrm{V} / \mathrm{W} \cdot \mathrm{m}^{-2}$ to around a hundred of $\mu \mathrm{V} / \mathrm{W} \cdot \mathrm{m}^{-2}$, for instance, a $50 \times 50 \mathrm{~mm}^{2}$ presents a sensibility of around $20 \mu \mathrm{V} / \mathrm{W} \cdot \mathrm{m}^{-2}$, and a $150 \mathrm{x}$ $150 \mathrm{~mm}^{2}$ presents a sensibility of around $120 \mu \mathrm{V} / \mathrm{W} \cdot \mathrm{m}^{-2}$; where their cost may reach the 600 euros each.

\subsubsection{Thermoelectric modules or Peltier modules}

Thermoelectric modules, also known as Peltier modules (referred here as TEM), are composed of several thermocouple junctions connected electrically in series and thermally connected in parallel, integrated between two ceramic plates [9] (see figure 2 (a)). These thermocouple junctions consist of a $\mathrm{n}$ - and a p-type semiconductor materials connected by small and thin copper tabs; the most common semiconductor materials employed are quaternary alloys of bismuth, tellurium, selenium, and antimony, e.g., $\mathrm{Bi}_{2} \mathrm{Te}_{3}$. There are still modules without ceramic plates, which have the advantage of eliminating the thermal resistance of the ceramic plate. They also 

electrical insulation and a high thermal conductance [9].

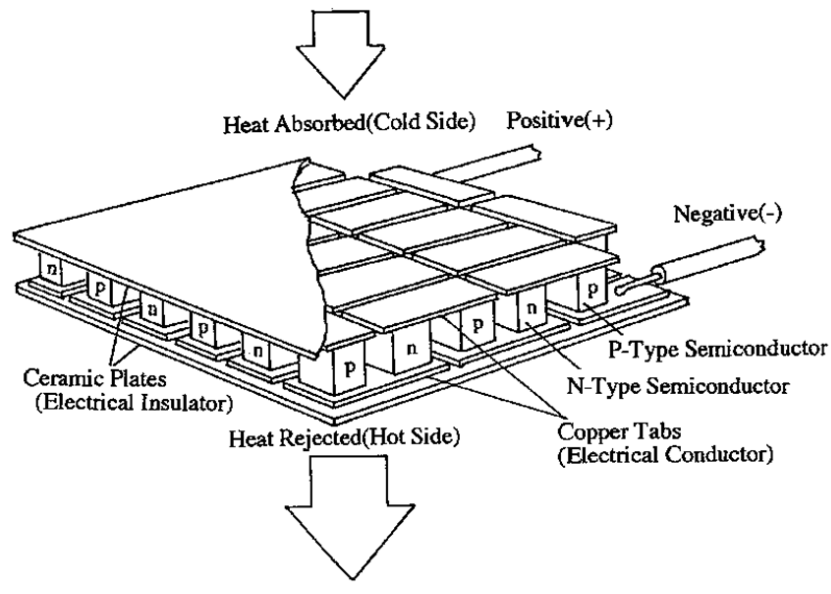

(a)

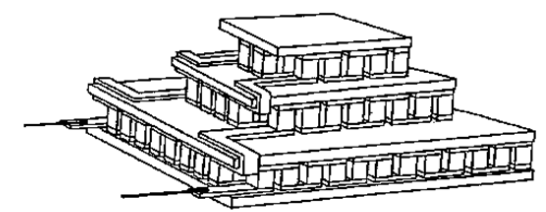

(1)

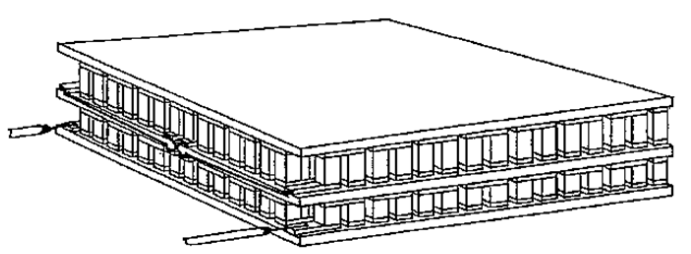

(2)

(b)

Figure 2. General structure of a thermoelectric module: (a) A single-stage TEM, and (b) two different multistage TEM configurations [9].

The thermoelectric properties of TEM vary with the average temperature of the thermoelectric n-p junctions (usually called: elements); generally, a polynomial correlation with second-order temperature terms is used. For a thermoelectric material of $n$ - and $p$ - type, the average value of the properties is used (value of $n+$ value of $p$ ) $/ 2$ [9]. In addition to the thermoelectric material properties, the module is characterized by two other parameters: GF, which represent the geometric factor of a single thermoelectric element and is given by $G F=S_{\text {element }} / e_{\text {element }}$, and $\mathrm{N}$ the number of $\mathrm{n}$ plus the number of $\mathrm{p}$ elements (sometimes the couple terminology is used: number of couples (N/2) [9]. Moreover, a thermoelectric module or a single thermoelectric element can be characterized by the total electric resistance $\left(R e_{T E M}\right)$ in $\Omega$, the total Seebeck coefficient $\left(a_{T E M}\right)$ in $\mathrm{V} \cdot \mathrm{K}^{-1}$, and the total thermal conductivity $\left(\lambda_{T E M}\right)$ in $\mathrm{W} \cdot \mathrm{K}^{-1}$, respectively: $R e_{T E M}=N \cdot \rho_{\text {element }} / G F, a_{T E M}=N \cdot a_{\text {element }}$, and $\lambda_{T E M}=N \cdot$ $\lambda_{\text {element }} \cdot G F$; the subscript "element" refers to the average value of the np thermoelectric couple.

These modules have been designed for many applications, for instance, in cooling application and electrical generation purposes; they name may differ depending on the application: thermoelectric cooler (TEC) where the TEM is use in "Peltier mode" and thermoelectric generator (TEG) where the TEM is use in "Seebeck mode", respectively. When used as thermoelectric cooler [8], their main function is to extract the heat from the surface they are placed on. To accomplish this main function, the TEM is normally connected to a DC power source, which, when turned on and depending on the connection polarity, i.e., positive with positive and negative with 
negative, will induced the creation of a temperature difference between both sides of the TEM. Each of the TEM sides are normally called cold $\left(T_{C}\right)$ and hot $\left(T_{H}\right)$ side. Then, the cold side is placed onto the surface wanted to be cool down and the hot surface is normally attached to a heat sink which is exposed to surrounding air; this heat sink is intended to enhance the heat transfer (as the function of an extended surface). When these modules are used for power generation, the hot and cold sides are disposed inversely and the electric terminals are connected to a load to power it.

For heat flux measurement or heat flux detection, they work in an open circuit configuration when connected to a multimeter or an acquisition system for data collection [5]. In this case, they follow a similar relation between the voltage generated when a heat flux is traversing the module (see eq. 1). Even though they may have the particularity of a $K$ coefficient dependent on temperature due to the semiconductor materials of the thermocouple junctions, and the time response is about one minute. The dimensions availability for this type of module is limited with respect to the availability of conventional heat flux meters.

\subsubsection{Experimental and analytical approaches for splitting the convective and radiative heat exchanges}

\section{Two heat flux sensors with contrasted emissivity}

\section{Experimental approaches}

The measurement of superficial heat exchanges, i.e., convection and radiation, using FGT sensors and TEM, have been a topic of interest of various researchers [1,3,11-16]. The interest lays in the possibility of splitting the convection and radiation parts from the heat flux measurement. Here we are focused on the implementation of such sensors for the estimation of both superficial heat exchanges; any other case was excluded. However, other research works have been found regarding the implementation of such sensors in thermal characterization of walls $[2,4,11]$

A technique to estimate the convection and radiation heat exchanges on a surface was implemented, consisting of using two FGT sensors, where one was to be coated with a black surface and the other with a shiny surface. Then, under the premise that the black and shiny surfaces had emissivity values close to 1 and 0 respectively, the former was said to estimate the total heat flux (convection + radiation) and the latter to estimate the convection heat flux on the rigid surface where they installed the sensors, e.g., heavyweight $[9,18,19]$ and lightweight walls, and isolate-type wall [11]. 
The disposition of the black and shiny heat flux sensors has differed from one study to the other, for instance, they were placed next to each other by one side with a separation between them [18,20], and with no separation between these two sensors $[3,16]$. A $10 \mathrm{~cm}$ separation between black and shiny was destined to the installation of a thermocouple to measure the local air temperature [20].

The use of conventional heat flux sensors coated with a thin polished aluminum foil was proposed for developing an experimental approach for measuring the convective heat transfer coefficient on heavyweight walls [19]. Results were found to agree with values reported in the literature for the case of laminar free convection along a vertical and isotherm heated plate.

More effort has been put into the estimation of the radiative heat flux. For instance, the development of a radiative heat flux sensor, based on the same reasoning mentioned earlier [12,14]. In this case, several black and shiny strips are placed next to each other intercalated and carefully wired as to superpose the electric potential given by each strip. This type of sensor only estimates the radiative heat flux directly from the sensor electrical response.

On the other hand, the implementation of Peltier modules is not as vast as for conventional heat flux sensors. Peltier modules were used for heat flux detection $\left(4 \times 4 \times 0,09 \mathrm{~cm}\right.$ and $\left.\sim 94 \mu \mathrm{V} / \mathrm{W} \cdot \mathrm{m}^{-2}\right)$, at the rear face, through an external wall of a building (see figure 3 (a)), where the front face of the wall was submitted to solar radiation heat flux and the rear face, to indoor air conditions. A heat dissipater (or heat sink) was installed on the sensor surface in contact with the indoor air, to increase the heat flow rate through the sensor. Experimental results were compared with simulation, finding an average absolute difference of $6,7 \pm 2,7 \%$ with maximum and minimum values of $10,5 \%$ and $0,1 \%$, respectively [5].

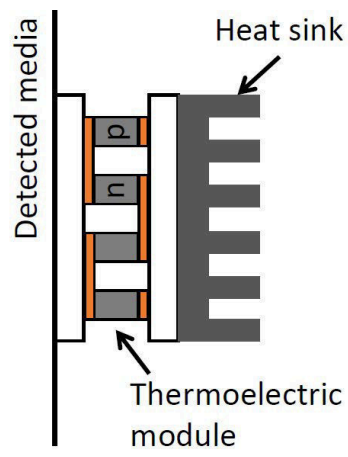

(a)

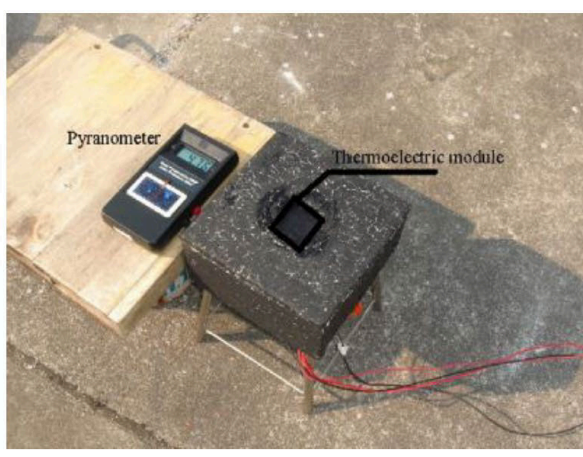

(b)

Figure 3. Experimental setup in Leephakpreeda 2012: (a) Installation on the rear face of a wall, and (b) for measuring solar radiation heat flux. 
These modules were also employed in the measurement of the solar radiation heat flux [5]. Here, the measurement of one module coated with black surface (see figure 10 (b)) was compared with a pyrometer. It was pointed out that satisfactory results were encountered as the average of the absolute differences was $4,8 \pm 3,9 \%$, which lead to conclude that the sensor measurement can be used for radiation heat flux without knowing the exact emissivity value of a black coating.

\section{Analytical approaches}

A way to separate more accurately convective and radiative parts from the heat flux measurement was proposed by [3]. The principle is based on a heat energy balance on the surface of the heat flux sensor, which is submitted to convection $\left(q_{C}\right)$ and radiation $\left(q_{R}\right)$ heat exchanges. The total heat flux $\left(q_{T}\right)$ on the sensor surface is equal to the sum of $q_{C}$ and $q_{R}$, and also, equal to the heat flux traversing the sensor $(q)$ :

It was stated that the heat flux measurement of each sensor (black and shiny), would have a convective and radiative part, owing to the emissivity value of the black and shiny coating employed: a black paint $(0,98)$ and a thin aluminum foil $(0,1)$, respectively, which are neither perfect emisors nor perfect reflectors. Thus, the convective part was determined by subtracting the radiative part from the shiny sensor measurement. This radiative part was estimated first, using the "classical radiosity method", compared latter with numerical simulation on the Fluent software. Results were also analyzed to study their dependence on the emissivity value of the black coating, by changing the latter from 0,9 to 1 (a perfect black body). It was found that increasing the emissivity yield to an increase in the total heat flux. Finally, it was concluded that the experimental procedure allows uncoupling the convection and radiation parts from the measurement since the relative error obtained was $5 \%$ maximum between the experimentation and numerical results. The heat flux levels in this experiment reached up to $350 \mathrm{~W} \cdot \mathrm{m}^{-2}$.

Douiri [16] based the analysis in equations 3 and 4, but wanted to estimate the convective heat transfer coefficient $\left(h_{C}\right)$ and the mean radiant temperature (here referred as $T_{\text {surr }}$ ), inside an oven. This consisted of defining the convective part using Fourier's convection equation. For the radiative part, the Kirchhoff's hypothesis for radiation heat transfer was employed. An expression for these two magnitudes $h_{C}, T_{\text {surr }}$ depending on several 
parameters, in which the temperatures $\left(T_{b}, T_{s}\right)$ and emissivities $\left(\varepsilon_{b}, \varepsilon_{s}: 0,93\right.$ and 0,1 , respectively) of both sensors played an important role, were drawn when solving the following, simultaneously:

$$
q_{b}=h_{C}\left(T_{\text {air }}-T_{b}\right)+\varepsilon_{b} \sigma\left(T_{\text {surr }}{ }^{4}-T_{b}{ }^{4}\right) \quad\left[\mathrm{W} \cdot \mathrm{m}^{-2}\right]
$$

This approach is under two hypotheses: having only one convective coefficient for both sensors, and the temperature measured by the sensor corresponds to that of its surface. The working heat flux ranges were of the order of $1500 \mathrm{~W} \cdot \mathrm{m}^{-2}$ for convection, and $500 \mathrm{~W} \cdot \mathrm{m}^{-2}$ for radiation.

\subsection{Special concerns about the heat flux sensors and purpose of the research}

\subsubsection{Calibration methods for converting the electrical response into heat flux}

The calibration process for heat flux sensors is usually employed to determine the sensor sensibility value $K$ and the perturbations it introduces, regarding its equivalent specific thermal capacity $C$ and its equivalent thermal resistance $R e$ [21]. The most common technique implemented for conventional heat flux sensors has been the zero-flux method [3,11-13,16,20-22].

This technique consists, basically, in having the heat flux sensor inside a well-isolated-chamber device, which contains (see figure 4): two flat heater resistors (having the same surface area as the sensor), an auxiliary heat flux sensor, and two water-recirculation-plates connected to a thermostatically-controlled water bath (used as heat sink). The sensor to be calibrated is placed over one of the water-recirculation-plates, and one of the heaters is placed over the sensor. The auxiliary sensor is placed over the heater to detect heat dissipation in the opposite desired direction. The auxiliary heater is placed over the auxiliary sensor, serving as heat flux compensation, which power is regulated to maintain a null signal response from the second sensor, ergo, ensuring a zero-heat flux through this sensor (wherefore the name zero-flux method). 


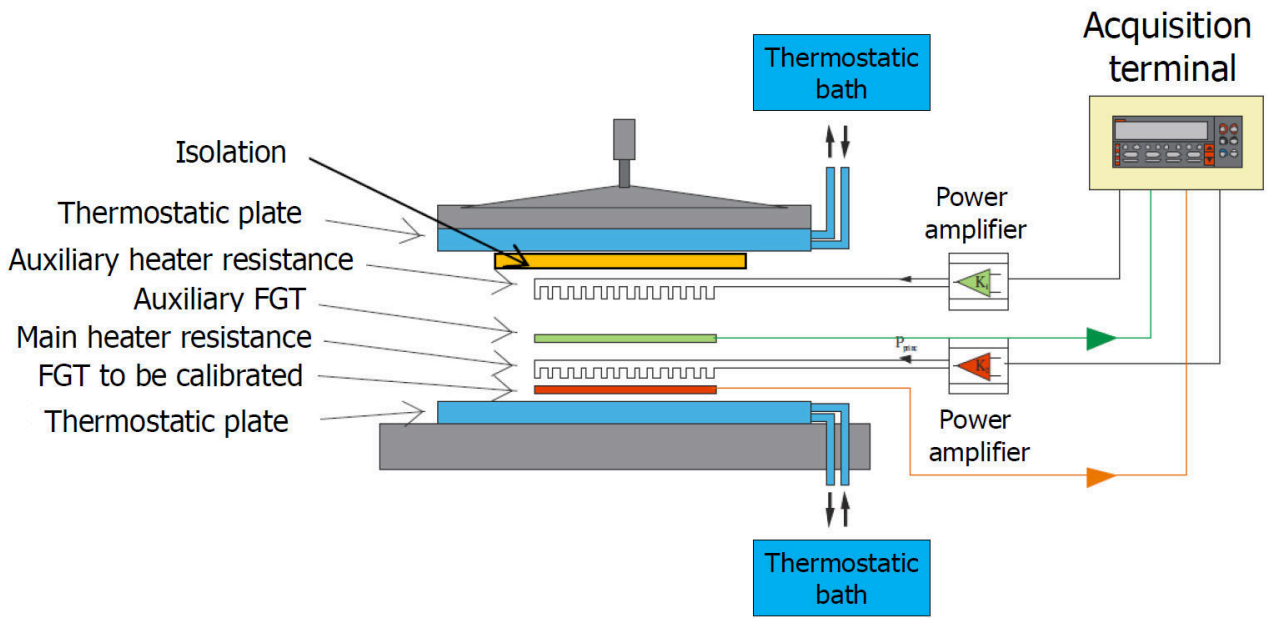

Figure 4. Schematic of the calibration apparatus employed for the zero-flux technique [18].

A profound study aimed to verify the sensibility value $K$, estimated by this calibration technique for the FGT, by implementing two numerical models of the multilayer system (see figure 4) using the governing equations of the physical phenomena that take place [22]. The simulation results showed the following: Only $39 \%$ of the sensibility value could be explained when using the perfect thermal-contact hypothesis between the copper and constantan layers inside the sensor, a value of the order of $1 \times 10^{-6} \mathrm{~K} \cdot \mathrm{m}^{2} \cdot \mathrm{W}^{-1}$ for the latter was enough to obtain a sensibility value identical to the one obtained by calibration, and the value of the contact resistance between the copper and constantan layers had a small influence on the sensor internal resistance $R e$ calculated, being consistent with the value obtained by calibration.

On the other hand, [5] performed a different approach for the calibration of Peltier modules. The sensibility value was determined indirectly by estimating the total Seebeck coefficient and the equivalent thermal conductivity. For the total Seebeck coefficient, the module was energized with a DC power source, where the electrical response of the module and the temperature difference between its both sides were measured after turning off the DC power. The Seebeck coefficient results from the slope of a fitted linear regression model. The thermal conductivity was estimated by the classical conductive method.

\subsubsection{Perturbations introduced by conventional heat flux meters: Captec ${ }^{\circledR}$ and TEM}

Various researchers have reported perturbations induced by both types of sensors when performing the heat flux measurement. For FGT, its measurements were compared with simulation results for two different cases, to estimate the errors in steady state [12] $\left(25 \times 25 \times 0,02 \mathrm{~cm}\right.$ and $\left.35 \mu \mathrm{V} / \mathrm{W} \cdot \mathrm{m}^{-2}\right):(i)$ the sensors placed on a vertical 
concrete wall (thermally heavyweight), (ii) the heat flux sensors placed on a polystyrene wall (thermal isolation). For the first case, the convection heat flux was encountered to be overestimated by near $26 \%$ and the radiation heat flux to be underestimated by practically $35 \%$. For the second case, the error on the radiation heat flux was around the $-79 \%$ and on the convection heat flux was between 250 and $350 \%$. For the case of isolate wall types, it was concluded that the estimation of the convective and radiative components is complexed and a temperature correction under the sensors is needed (in the sensor-wall interface, $T_{s}{ }^{\prime}$ ), where errors were said to be mainly caused by the local temperature modifications on the wall surface, due to the presence of the sensors, which also modifies the heat flow distribution through the wall thickness; this was also pointed out in $[8,13,18]$.

In transient state, when a FGT sensor is placed onto a surface, it will absorb the heat flow at the same rate as the wall if their thermal effusivity values are the same. The condition that the sensor heat storage capacity is negligible concerning the heat flow traversing it, must be verified to perform measurements in a transient state [12]. Finally, the measurement error is proportional to the mismatching between the sensor and the wall, i.e., the difference between the effusivities $\sqrt{\lambda \rho c_{p}}$ and $\sqrt{C / R}$ of both, the sensor and the wall [12].

In the use of TEM as heat flux sensors, [5] compared experimental results, from the heat flow detection through an external wall, with simulation, and pointed out that the amount of the detected heat flow through the wall was not identical to the amount that would be detected without the use of a sensor. Two reasons were given to explain this difference: The changes in the wall boundary conditions, and the effect of the thermal contact resistance between the thermoelectric module and the wall.

Two types of heat flux sensors have been implemented in the present investigation: commercial TEM and FGT of the type $\operatorname{Captec}{ }^{\circledR}$. As it has been encountered in the reported literature, FGT sensors are widely used having been proven to perform satisfactory enough in the decoupling of the convective and radiative parts of the heat flux measurements. Here, instead, we aim to propose a measurement device using TEM for the heat flux measurement along with a rather simplify decoupling model. A comparison between TEM and FGT is made.

\section{Description and configuration of the setup for heat flux measurements}

To perform the heat flux measurement, Peltier modules with dimensions of $3 \times 3 \times 0,48 \mathrm{~cm}$ and an average sensitivity value of $239 \pm 3 \mu \mathrm{V} / \mathrm{W} \cdot \mathrm{m}^{-2}$, and Captec heat flux sensors with dimensions of $15 \times 15 \times 0,05 \mathrm{~cm}$ with an average $K$ value of $125 \pm 3 \% \mu \mathrm{V} / \mathrm{W} \cdot \mathrm{m}^{-2}$ according to the manufacturer, are implemented here. 

need to be calibrated in order to find the proportional constant coefficient that allow to convert their electrical response into heat flux, as also mentioned earlier. Thus, the following section presents the calibration apparatus and procedure followed to determine the sensitivity value $\boldsymbol{K}$ of our Peltier modules.

Before any implementation, the surface of the both the Peltier modules and Captec heat flux sensors were covered with black and shiny coatings as to form couples of black-shiny heat flux sensors (one black and one shiny sensor) (see figure 5 (a)). Also, the edges-sides of each Peltier module were covered with silicon paste with the purpose of isolating the thermocouple inserted in the Peltier module from the surrounding air (see figure 5 (b)).

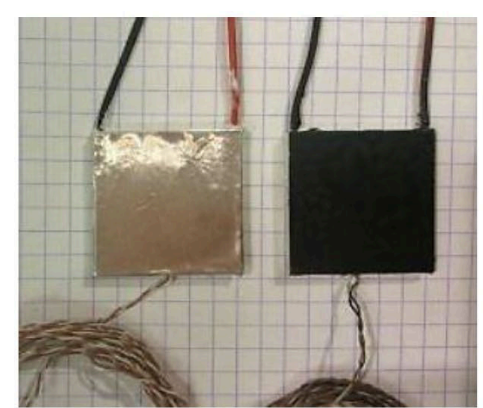

(a)

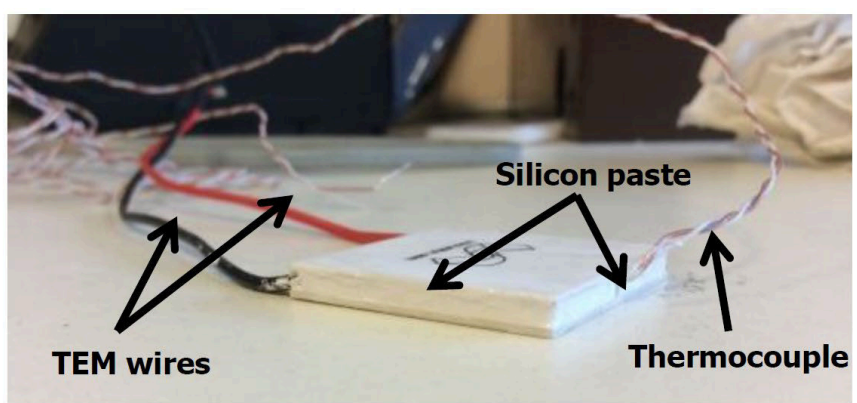

(b)

Figure 5. (a) Images of a shiny thermoelectric module, (b) black-shiny couple of TEM, and (c) Peltier module with an inserted thermocouple wrapped with white silicon paste.

The calibration apparatus is shown in figure 6 and is based on the zero heat flux method consisting of: (a) a power supplier ISO-TECH-IPS 303DD, (b) heavy blocks to assure contact, (c) a calorimeter with the heat and heat flux meter inside, (d) a DC power supply VELLEMAN LABPS 3005D to power the heating resistance, and together (e) and (f) group a PID controller RKC INSTRUMENT INC CB100/400/500/700/900 to regulate the temperature of the calorimeter's chamber, and the measuring system with a LabView interface.

The calorimeter (see figure 6 left) is composed by four principal layers: the first layer is made of a woodenlike isolation material commonly used; the second layer is made of a thick black isolation material (element 1) the proportion of a uniform heat load sent to the sensor. 

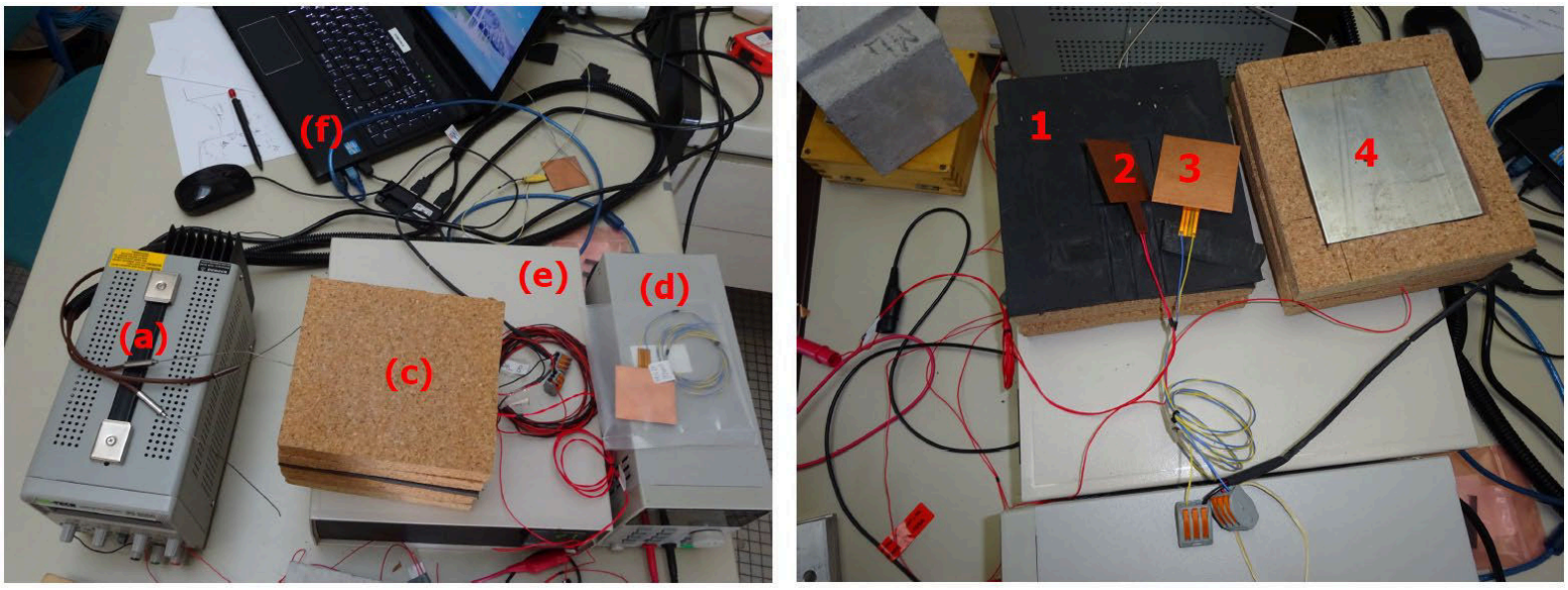

Figure 6. Calibration apparatus. On the left: (a) DC power supply 1, (b) support, (c) calorimeter, (d) DC power supply 2, (e) PID temperature controller, and (f) measuring system and PC interface. On the right: (1) Thick isolation layer, (2) heating resistance, (3) Captec ${ }^{\circledR}$ heat flux sensor, (4) heat sink.

On the other side of the heating resistance are several straight lines. This side is in contact with the thick black isolation material to reduce any eventual heat losses in a non-desire direction. Additionally, part of the thick black isolation material is cut out to make space to fit the heating resistance, also to avoid any undesirable horizontal heat losses. Also, in this third layer, is the heat flux meter to be calibrated or characterized which is in direct contact with the heating resistance (see figure 6 left, element 3). The fourth layer corresponds to an aluminum block enclose with wooden-like isolation material, which serves as a heat sink. This heat sink aide the heat dissipated from the heating resistance and traversing the heat flux meter, to reduce any heat storage in the latter.

The calibration procedure is based on a stability criterion which is set by the user in the LabView interface. This criterion corresponds to the desired standard deviation value on the electrical response (in volts) of the heat flux sensor, when a constant heat flux is sent to the heat flux sensor. The latter is accomplished when a constant voltage setpoint is applied to the heating resistance. When this stability criterion is reached, the system changes the voltage applied to the heating resistance to the next voltage setpoint assigned, also set by the user. 
The validation of the calibration procedure and apparatus was performed by calibrating a Captec heat flux sensors of known sensitivity value. The Captec heat flux sensor used here $(5 \times 5 \times 0,05 \mathrm{~cm})$ has a sensitivity value of $21,4 \mu \mathrm{V} / \mathrm{W} \cdot \mathrm{m}^{-2}$, as provided by the manufacturer.

The calibration procedure performed was the same as the one described here before. The voltage setpoints applied to the heating resistance are presented in table 1. Also, in this table, the resulting heat flux sent by the heating resistance is presented; this heat flux is calculated by using the surface area of Captec $0,0025 \mathrm{~m}^{2}$ and the resulting electric current (I) along with the equation $q=V \cdot I / S$. In this case, a heating resistance of $4 \times 4 \mathrm{~cm}^{2}$ $(17,3 \Omega)$ was used. It is worth mentioning that better sensitivity values (closer to the manufacturer's value) were encountered when using the surface area of Captec to calculate the heat flux, instead of that of the heating resistance. Using the former leads to a sensitivity value of $20,7 \mu \mathrm{V} / \mathrm{W} \cdot \mathrm{m}^{-2}$ which is at $3 \%$ close to the manufacturer's reported value. On the contrary, using the surface area of the heating resistance leads to a sensitivity value at $38 \%$ close to the manufacturer's reported value.

Table 1. Calibration results from validation with $\operatorname{Captec}{ }^{\circledR}$ heat flux sensors and sensitivity values.

\begin{tabular}{|c|c|c|c|c|}
\hline \multicolumn{2}{|c|}{$\begin{array}{c}\text { Voltage setpoints } \\
\qquad V[\mathrm{~V}]\end{array}$} & $\begin{array}{c}\text { Resulting Current } \\
\text { I [A] }\end{array}$ & $\begin{array}{c}\bar{U} \text { FGT } \\
{[\mu \mathrm{V}]}\end{array}$ & $\begin{array}{c}\bar{q} \\
{\left[\mathbf{W} \cdot \mathbf{m}^{-2}\right]}\end{array}$ \\
\hline \multicolumn{2}{|r|}{0,5} & 0,028 & 173 & 5,6 \\
\hline \multicolumn{2}{|r|}{1} & 0,055 & 456 & 22 \\
\hline \multicolumn{2}{|r|}{1,5} & 0,085 & 1066 & 51 \\
\hline \multicolumn{2}{|r|}{2} & 0,113 & 1857 & 90 \\
\hline \multicolumn{2}{|r|}{2,5} & 0,141 & 2932 & 141 \\
\hline Tests & $\begin{array}{c}K\left[\boldsymbol{\mu} \mathbf{V} / \mathbf{W} \cdot \mathbf{m}^{-}\right. \\
\left.{ }^{2}\right]\end{array}$ & $\mathbf{R}^{2}$ & Stability criterion $[\mu \mathrm{V}]$ & Relative error [\%] \\
\hline 1 & 20,75 & 0,9993 & $1 \times 10^{-6}$ & 3,1 \\
\hline 2 & 20,55 & 0,9997 & “" & 4,0 \\
\hline 3 & 20,86 & 0,9998 & “" & 2,5 \\
\hline 4 & 20,24 & 0,9996 & “ & 5,4 \\
\hline 5 & 20,66 & 0,9995 & $1 \times 10^{-7}$ & 3,5 \\
\hline 6 & 20,34 & 0,9995 & "“ & 5,0 \\
\hline
\end{tabular}


The Captec sensor electrical response $(\bar{U}$ FGT) was plotted against the averaged heat flux applied $(q)$, where after repeating the procedure various times, the resulting sensitivity values are presented in table 1 . The sensitivity value was determined by fitting a linear regression model forced to cross the origin. Better fitting results are obtained when taking the average value $(\bar{U})$. From these results, the accuracy of the proposed calibration setup and procedure may be established as to be $4,0 \pm 1,0 \%$.

\subsubsection{Calibration of Peltier modules}

Peltier modules $\left(3 \times 3 \times 0,48 \mathrm{~cm}^{3}\right.$ and $\left.3 \times 3 \times 0,37 \mathrm{~cm}^{3}\right)$ were calibrated using the calibration apparatus and procedure described in $\$ 2.1$, with a heating resistance of the same size as the modules. This procedure was performed several times to observe repeatability, where an average value for the sensitivity $K$ was encountered to be $239 \mu \mathrm{V} / \mathrm{W} \cdot \mathrm{m}^{-2}$ for the $3 \times 3 \times 0,48 \mathrm{~cm}^{3}$ module, and $109 \mu \mathrm{V} / \mathrm{W} \cdot \mathrm{m}^{-2}$ for the $3 \times 3 \times 0,37 \mathrm{~cm}^{3}$ module (some results are presented in table 2). The uncertainty of the sensitivity value depends of various factors: The uncertainty of the measuring system $(0,3 \%$ of reading +1 digit $\mu \mathrm{V})$, the power source $(0,01 \mathrm{~V}$ and $0,001 \mathrm{~A})$ or the heating resistance employed, the surface sensor $\left(1,2 \times 10^{-6} \mathrm{~m}^{2}\right)$. Also, the reported uncertainty value of sensitivity should account for the validation relative error presented at the end of the previous subsection.

Table 2. Calibration results for the TEM with a heating resistance size of $3 \times 3 \mathrm{~cm}$.

\begin{tabular}{|c|c|c|c|c|c|c|}
\hline Tests & $\begin{array}{l}\boldsymbol{K}\left[\boldsymbol{\mu} \mathbf{V} / \mathbf{W} \cdot \mathbf{m}^{-2}\right] \\
\left(3 \times 3 \times 0,48 \mathrm{~cm}^{3}\right)\end{array}$ & $\mathbf{R}^{2}$ & $\begin{array}{c}\text { Stability } \\
\text { criterion }[\mu \mathrm{V}]\end{array}$ & $\begin{array}{l}\boldsymbol{K}\left[\boldsymbol{\mu} \mathbf{V} / \mathbf{W} \cdot \mathbf{m}^{-2}\right] \\
\left(3 \times 3 \times 0,37 \mathrm{~cm}^{3}\right)\end{array}$ & $\mathbf{R}^{2}$ & $\begin{array}{c}\text { Stability } \\
\text { criterion }[\mu \mathrm{V}]\end{array}$ \\
\hline 1 & 237 & 0,9997 & $1 \times 10^{-15}$ & 108 & 0,9993 & $1 \times 10^{-10}$ \\
\hline 2 & 236 & 0,9997 & "، & 107 & 0,9999 & "، \\
\hline 3 & 240 & 0,9994 & "، & 110 & 0,9998 & "، \\
\hline 4 & 242 & 0,9996 & " & 110 & 0,9987 & " \\
\hline
\end{tabular}

The calculation of the uncertainty in the sensitivity value $K$ was performed by following the Constant Odds Combination (COC) method, presented in [23]. The sensitivity value can also be determined equation 1 , where $q=V I / S$, giving $K=U S / V I$. When applying the COC method to the latter, yields the uncertainty in the sensitivity $\delta_{K}$ : 
394

where $\delta_{U}, \delta_{S}, \delta_{I}$, and $\delta_{V}$, are the uncertainty values of the devices part of the calibration apparatus.

The resulting sensitivity value for Peltier modules are: $239 \pm 3 \mu \mathrm{V} / \mathrm{W} \cdot \mathrm{m}^{-2}$ for the ones with dimensions $3 \times 3 \times 0,48$ $\mathrm{cm}^{3}$, and $109 \pm 7 \mu \mathrm{V} / \mathrm{W} \cdot \mathrm{m}^{-2}$ for the ones with dimensions $3 \times 3 \times 0,37 \mathrm{~cm}^{3}$.

The uncertainty in the direct heat flux measurement from the sensors $\left(\delta_{q}\right)$, were also determined using the COC method applied to equation 1 . The uncertainty of the heat flux measurement from Peltier modules was encountered to strongly depend on the current value of the heat flux measured: $0,5 \mathrm{~W} \cdot \mathrm{m}^{-2}$ between 0 to $20 \mathrm{~W} \cdot \mathrm{m}^{-2}$. A constant sensitivity value was admitted here for Peltier modules, since the thermoelectric properties do not significantly vary among the working temperatures of the experiments. Captec heat flux meters have an average uncertainty of $1,36 \mathrm{~W} \cdot \mathrm{m}^{-2}$ in a range of 0 to $30 \mathrm{~W} \cdot \mathrm{m}^{-2}$, and the type $\mathrm{T}$ thermocouple have a maximum uncertainty of $0,48^{\circ} \mathrm{C}$.

\section{Validation of the use of TEM and the decoupling model}

\subsection{Estimation of convective and radiative heat exchanges}

\subsubsection{The measurement device}

Based on the experimental setup proposed by former researchers, the setup implemented here (called "measurement device") consists of the following components (see figure 7):

a) A couple of one black and one shiny coated Peltier modules installed with a small separation between them, as to expose all their sides to the air. These sensors were properly placed onto the surface studied using a silicon-based thermal grease with thermal conductivity of $5 \mathrm{~W} \cdot \mathrm{m}^{-1} \cdot \mathrm{K}^{-1}$.

b) A type $\mathrm{T}$ thermocouple to measure the air temperature at $10 \mathrm{~cm}$ above the surface studied (without radiation shield).

c) A type $\mathrm{T}$ thermocouple inserted among the semiconductors elements of the module to measure the temperature of the surface studied. This thermocouple was coated with nail polish, for electrical insulation purposes, before inserting it into the modules. 


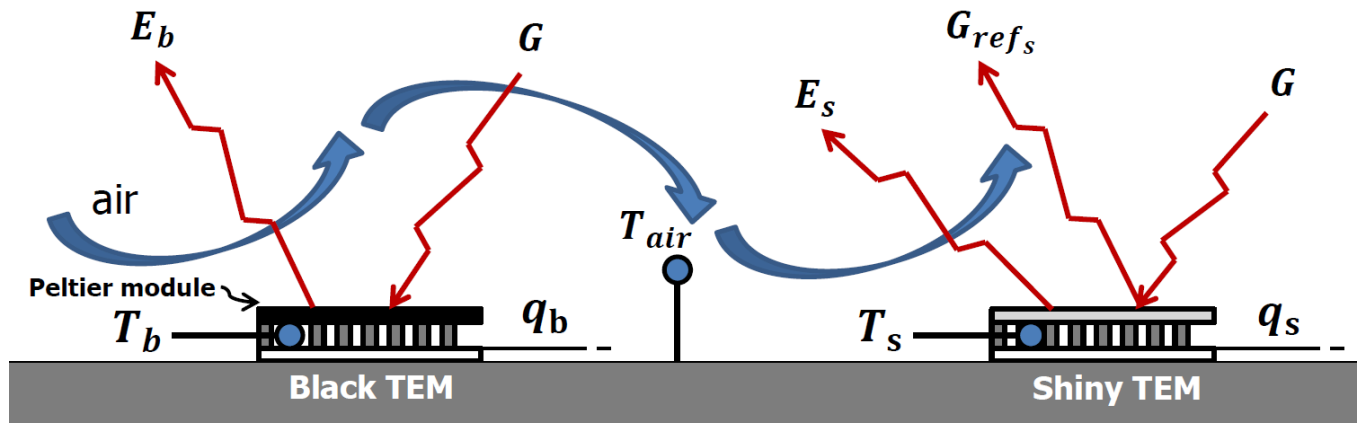

Figure 7. Representation of the convective and radiative heat exchanges over the measurement device.

\subsubsection{Decoupling model for the convective and radiative heat exchanges}

An analytical model is proposed here to distinguish the convective and radiative parts from the heat flux measurement. This model is based on a heat flux balance written for the considered surface $i$, as done by former researchers. A heat flux balance of the convective and radiative heat exchanges over this surface, as represented in figure 7, can be written for each black $(b)$ and shiny $(s)$ Peltier sensor, as follows:

$$
q_{b}=q_{R_{b}}+q_{C_{b}}=\alpha_{b} G-\varepsilon_{b} \sigma T_{b}^{4}+h_{C} \Delta T_{b} \quad\left[\mathrm{~W} \cdot \mathrm{m}^{-2}\right]
$$

where $q$ represents the total heat flux entering or the absorbed heat flux by the surface, $\varepsilon$ represents the thermal emissivity and $\sigma$ represents the Stefan-Boltzmann constant. Together $G, G_{r e f_{i}}$, and $E$, represent the net radiative heat exchanged between the surface and the surrounding environment $\left(q_{R}\right)$; where $G$ is the total incident radiation (short and long wavelength), $G_{r e f_{i}}$ is the reflected part of the total incident radiation, and $E$ is the emitted radiation. The term $G-G_{r e f_{i}}$ in equation 3 is equal to the absorbed part of the total incident radiation $\left(G_{a b s}\right)$, which can be written in terms of the thermal absorptivity ( $\alpha$ ) of the surface as $\alpha_{i} G$. The convective heat flux is represented by Fourier's law of convection, where $h_{C}$ is the convective coefficient and $\Delta T_{i}$ is the temperature difference between the nearby air and the surface $i$. For the emitted radiation heat flux $E$, Stefan-Boltzmann's law of the radiation power emitted by a black body is considered, along with the assumption that each surface behaves as a gray surface. 

the same for all sensors among the measurement device. Then, by solving together equations 8 and 9 , for $G$ and $h_{C}$ yields:

$$
G=\frac{\Delta T_{b}\left(q_{s}+\varepsilon_{S} \sigma T_{s}{ }^{4}\right)-\Delta T_{S}\left(q_{b}+\varepsilon_{b} \sigma T_{b}{ }^{4}\right)}{\alpha_{S} \Delta T_{b}-\alpha_{b} \Delta T_{S}} \quad\left[\mathrm{~W} \cdot \mathrm{m}^{-2}\right]
$$

$$
h_{C}=\frac{\alpha_{s}\left(q_{b}+\varepsilon_{b} \sigma T_{b}{ }^{4}\right)-\alpha_{b}\left(q_{s}+\varepsilon_{S} \sigma T_{s}^{4}\right)}{\alpha_{s} \Delta T_{b}-\alpha_{b} \Delta T_{S}} \quad\left[\mathrm{~W} \cdot \mathrm{m}^{-2} \cdot \mathrm{K}^{-1}\right] .
$$

449

450

451

453

454

455

456

457

458

459

460

461

462

463

464

465

Thus, by replacing equation 11 into Fourier's definition of convection for the shiny heat flux sensor presented in equation 9 , the convective heat flux, yields:

$$
q_{C_{s}}=\left(\frac{\alpha_{b} \Delta T_{s}}{\alpha_{b} \Delta T_{s}-\alpha_{s} \Delta T_{b}}\right) q_{s}-\left(\frac{\alpha_{s} \Delta T_{s}}{\alpha_{b} \Delta T_{s}-\alpha_{s} \Delta T_{b}}\right) q_{b}+\frac{\Delta T_{s} \sigma\left(\alpha_{b} \varepsilon_{s} T_{s}{ }^{4}-\alpha_{s} \varepsilon_{b} T_{b}{ }^{4}\right)}{\alpha_{b} \Delta T_{s}-\alpha_{s} \Delta T_{b}} \quad\left[\mathrm{~W} \cdot \mathrm{m}^{-2}\right]
$$

a similar expression is obtained for the convective heat flux for the black heat flux meter, just by replacing $\Delta T_{s}$ for $\Delta T_{b}$. It can be inferred from equation 12 that assuming that the convective heat flux would be entirely determined by a heat flux meter coated with a shiny-foil, leads to an overestimation of this heat flux, and this, by considering only the radiative properties of the surface and the air-surface temperature difference of both sensors. In turn, this equation shows that the convective heat flux would be determined by the shiny heat flux meter only if: $(i)$ both sensors would have the same temperature, (ii) the radiative properties of the shiny heat flux meter would have values of exactly zero, respectively. Note here that if the latter holds, the knowledge of the radiative properties of the black coating is not important which seems fairly straightforward to conceive because in such a case, a black heat flux would not be needed. If only item (i) holds, the convective component for both heat flux meters would be the same, and if in addition to this, (iii) the emissivity values is considered to be equal to the absorptivity values, i.e., a radiative environment where long wavelength heat radiation dominates at room temperature, the last term of equation 12 would be null and the convective heat flux would strongly depend on the emissivity values.

Nevertheless, equation 12 implies that the convective heat flux would be estimated then, without consideration of the surface morphology. For instants, if the morphology of the sensors, e.g., their thickness, which might considerably modify the relevant properties of the surface in which they are installed, then this would also yield into an overestimation of the convective heat flux. 

$q_{C_{b}}$ from $q_{b}$, which yields:

$$
q_{R_{b}}=q_{b}-\left[\frac{\left(\alpha_{s}-\alpha_{b}\right) \Delta T_{b}}{\alpha_{s} \Delta T_{b}-\alpha_{b} \Delta T_{s}}\right] q_{s}+\frac{\Delta T_{b} \sigma\left(\alpha_{b} \varepsilon_{S} T_{s}{ }^{4}-\alpha_{s} \varepsilon_{b} T_{b}{ }^{4}\right)}{\alpha_{s} \Delta T_{b}-\alpha_{b} \Delta T_{S}} \quad\left[\mathrm{~W} \cdot \mathrm{m}^{-2}\right]
$$

475

Note that from expression 13, if one were to have a shiny coating with perfect radiative properties (meaning that $\varepsilon_{S}$ and $\alpha_{s}$ are equal to 0 ), one might assume that the value of the maximum net radiation heat exchange $q_{R-b}$ would depend on the radiative properties of the black coating. However, in such a case, it can be shown with expression 13 that the knowing of the radiative properties of the black coating becomes unnecessary when $\varepsilon_{s}$ and $\alpha_{s}$ equal 0 . In turn, the value of the net radiative heat exchange would depend on the value of $\Delta T_{b}$ and $\Delta T_{s}$, in addition to the difference between $q_{b}$ and $q_{s}$, resulting in: $q_{R_{b}}=q_{b}-\frac{\Delta T_{b}}{\Delta T_{s}} q_{s}$. Note here that the previous formulation do not treat the possible temperature modification that the heat flux sensors may introduced, this formulation only accounts for the difference between the black and shiny heat flux sensors.

A sensitivity analysis showed that the estimation of the convective (see eq. 12) and radiative (see eq. 13) heat fluxes is strongly influenced by the uncertainty in the emissivity values of the shiny coating, where a precise determination of the emissivity is required, with an uncertainty value around or smaller than $1 \times 10^{-2}$.

The emissivity values of both black and shiny coatings and the Captec surface were determined by following the procedure proposed on ISO 18434-1:2008(E). A black paint (NEXTEL Velvet Coating 811-21) with emissivity of 0,97 was used as the known-emissivity reference surface. The resulting emissivity values for each surface were: $0,953 \pm 0,012$ and $0,069 \pm 0,014$ for the black and shiny coatings, respectively. The emissivity value obtained for Captec heat flux meter was 0,12 .

\subsection{Experimental study: Case of weak convective and radiative heat flux under in situ conditions}

An experimental study was conducted in a naturally ventilated Plus Energy House prototype (see figure 8) carried out during the summertime in 2016 in Southwest France. This study aimed to highlight the energy charge and discharge processes of a $68 \mathrm{~mm}$ thick concrete-slab located in the living room floor, which was submitted to different heat exchanges, resulting of the implementation of a configuration of the platform natural ventilation 
automated system. Within this study, the proposed measurement device using TEM (see figure 7) was installed at one location on the concrete slab surface as shown in figure 8 (c) red square. Aside this measurement device, one black and one shiny FGT sensors were installed, to assure that the four sensors are submitted to the same conditions.

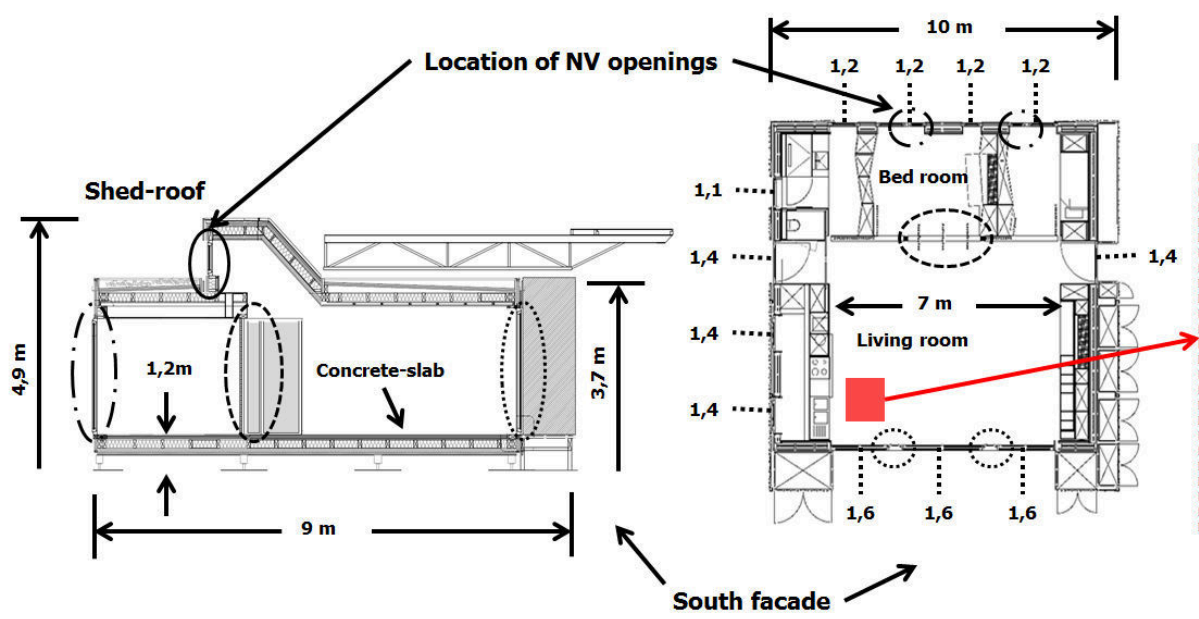

(a) (b)

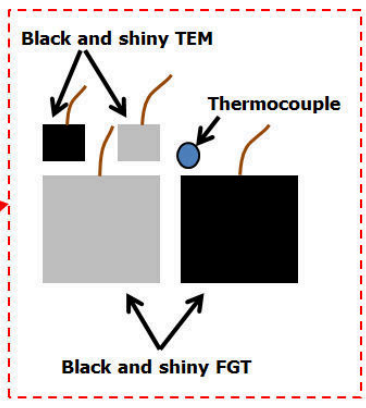

(c)
504

505

506

507

508

509

510

511

512

513

514

515

516

517

518

519

520

521

Figure 8. Schematic of the architectural plan of the experimental platform: (a) West view, (b) top view, and (c) black-shiny couples of TEM and FGT.

As the only ongoing system of the PEH implemented in this study was the natural ventilation automated system, the experimental protocol implemented for the measurement campaigns during fall in November 2016, consisted of the following points: Experimental data were collected continuously, from 2/11 to 7/11, at a sampling rate of one minute, and from $18 / 11$ to $21 / 11$, at a sampling rate of five seconds. The solar shades were kept permanently closed during the measurement campaigns, and the natural ventilation openings were controlled manually. Only the openings at the south facade and the Shed-roof were functional; the openings at the north facade remained closed. The platform was unoccupied during the measurement campaigns, and the lights remained turned off. However, two computers remained operational; one for data collection and one for controlling the natural ventilation openings. Since the inside of the platform is divided into four zones: the living room, bedroom, bathroom, and toilet; all doors dividing these zones were kept opened.

\subsection{Results and discussion}

This section presents the experimental results obtained from the measurement campaigns described in $\S 3.2$ and a respective discussion. This section is organized as follows: All direct measurements, after calibration applied, 
522

523

524

525

526

527

528

529

530

531

532

533

534

535

536

537

538

539

540

541

542

543

544

545

546

are first presented in a subsection $\$ 3.3 .1$ to evaluate any difference between TEM and FGT sensors; that is to say, the direct heat flux measurements from the black and shiny Peltier modules $\left(q_{b_{T E M}}, q_{S_{T E M}}\right)$ and black and shiny Captec $\left(q_{b_{F G T}}, q_{S_{F G T}}\right)$, respectively, and their temperatures (measured inside each sensor), along with the air temperature. This before is followed by $\S 3.3 .2$, where the estimation of the convective and radiative heat fluxes using the results in $\S 3.3 .1$, and equations 12 and 13 for $\operatorname{TEM}\left(q_{b_{F G T}}, q_{S_{F G T}}\right)$ and FGT $\left(q_{b_{F G T}}, q_{S_{F G T}}\right)$. The distinction of whether they are calculated from TEM or FGT measurements is made through all these results. It should be noted that a positive heat flux value indicates a heat flux entering the surface in question. Conversely, a negative heat flux value indicates a heat flux leaving the surface. Only the moments where the natural ventilation openings were kept opened is shown in the graphs.

\subsubsection{Direct measurements from the heat flux meters: $q_{b}, q_{s}, T_{b}, T_{s}, \Delta T_{s}, \Delta T_{b}$}

A significant difference can be observed in figure 9 between the heat flux measurement from the black TEM $\boldsymbol{q}_{\boldsymbol{b}_{T E M}}$ and FGT $\boldsymbol{q}_{\boldsymbol{b}_{F G T}}$ (a), and from the shiny TEM $\boldsymbol{q}_{s_{T E M}}$ and FGT $\boldsymbol{q}_{s_{F G T}}$ (b). Both heat fluxes measured by the TEM $\boldsymbol{q}_{\boldsymbol{b}_{T E M}}$ and $\boldsymbol{q}_{s_{T E M}}$ (black lines) appears to be, at some points, significantly larger than the one measured by the FGT $\boldsymbol{q}_{\boldsymbol{b}_{F G T}}$ and $\boldsymbol{q}_{s_{F G T}}$ (blue lines), specially when the natural ventilation openings are opened (gray regions). When plotting the heat flux measured by the TEM against the FGT (see figure 10 (a)), the straight line found indicates that the measurements from both TEM and FGT followed very similar behavior. Also, a linear regression model applied to these straight lines showed that the TEM measurement is about 2,5 times larger than the FGT measurement: $\boldsymbol{q}_{s_{T E M}}=(\mathbf{2}, \mathbf{5}+(+\mathbf{2} / \mathbf{- 1 . 6})) \boldsymbol{q}_{s_{F G T}}, \mathrm{R}^{2}=0,9905$ for the shiny ones, and $\boldsymbol{q}_{b_{T E M}}=\mathbf{1}, \mathbf{7} \boldsymbol{q}_{\boldsymbol{b}_{F G T}}, \mathrm{R}^{2}=$ 0,9758 for the black ones.

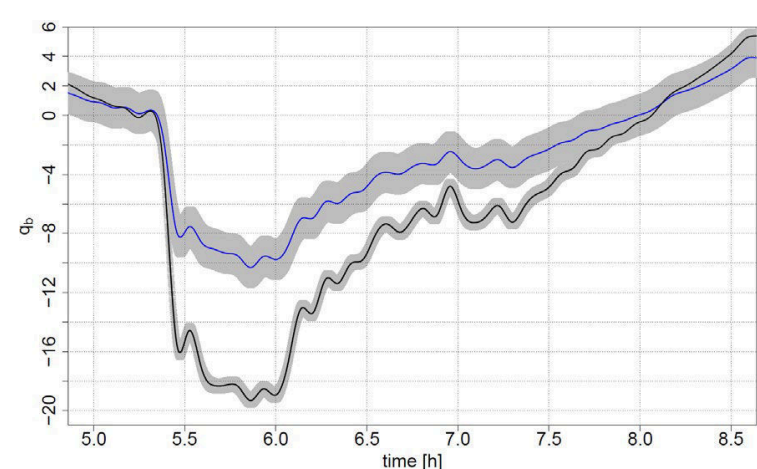

(a)

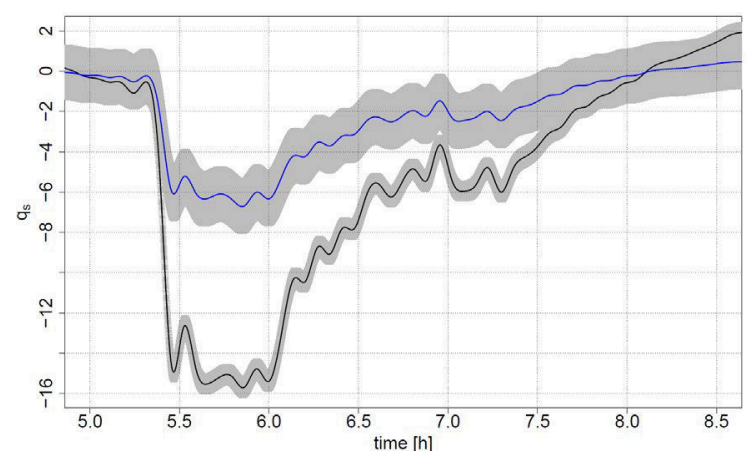

(b)

Figure 9. Heat flux measurements from TEM (in black) and from FGT (in blue): (a) $\boldsymbol{q}_{\boldsymbol{b}_{T E M}}$ and $\boldsymbol{q}_{\boldsymbol{b}_{F G T}}$, and (b) $\boldsymbol{q}_{s_{T E M}}$ and $\boldsymbol{q}_{s_{F G T}}$. Uncertainties are presented by the bands. 


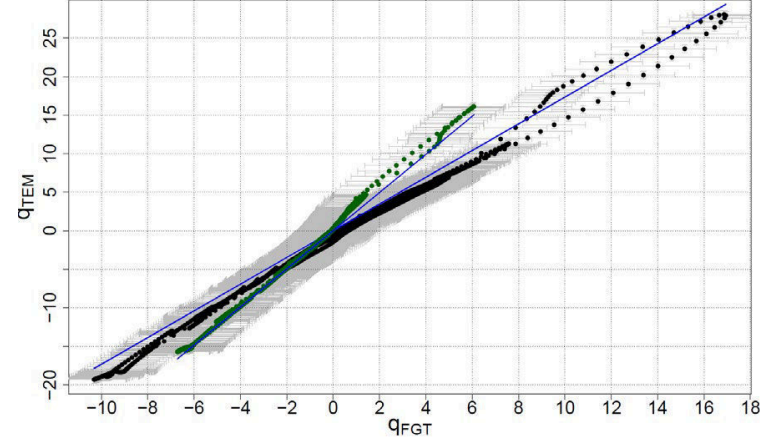

(a)

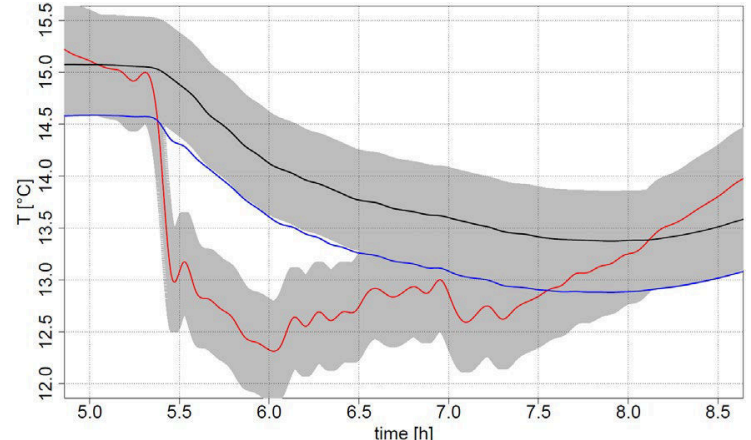

(b)
549

550

551

552

553

554

555

556

557

558

559

560

561

562

563

564

565

566

567

Moreover, figure 10 (b) shows that a difference is also encountered in the temperature measurements inside the TEM and FGT. When the former and latter are plotted against each other, the linear regression model shows that the difference is of approximately $0,5{ }^{\circ} \mathrm{C}$. This difference might be associated with the calibration of the thermocouples inside the TEM, since the temperature measurement connectors inside FGT were employed as given by the manufacturer.

\subsubsection{Convective and radiative heat flux: $q_{C}, q_{R}$}

After using equations 12 and 13 to compute the convective and radiative heat flux separately from TEM and FGT measurements presented previously, the difference encountered between the heat flux measurements of TEM and FGT also persists in the estimation of the convective component, as shown in figure 11: $\boldsymbol{q}_{C_{T E M}}=(\mathbf{2}, \mathbf{5}+$ $(+\mathbf{2} / \mathbf{- 1}, \mathbf{5})) \boldsymbol{q}_{C_{F G T}}, \mathrm{R}^{2}=0,9779$, and $\boldsymbol{q}_{\boldsymbol{R}_{T E M}}=\mathbf{1}, \mathbf{1} \boldsymbol{q}_{\boldsymbol{R}_{F G T}}, \mathrm{R}^{2}=0,9936$.

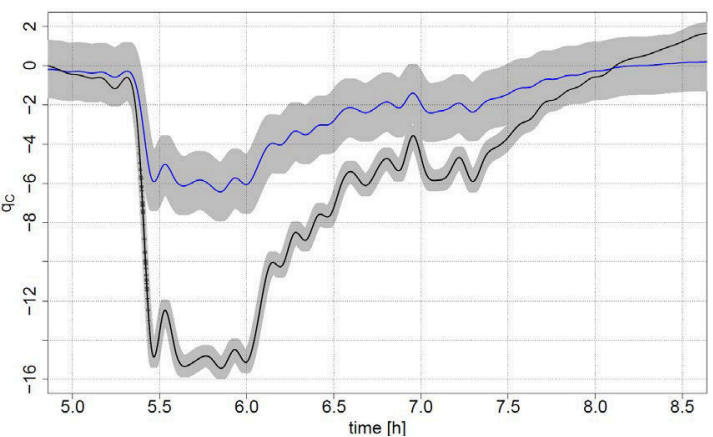

(a)

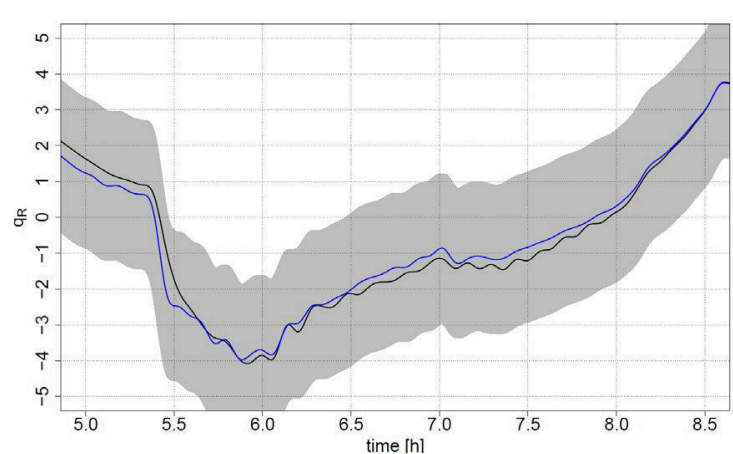

(b)

Figure 11. Heat flux from TEM (in black) and FGT (in blue): (a) Convective, and (b) Radiative. 

coating employed. In fact, it can be shown with equation 12 that the direct measurement from the shiny TEM will get far from the estimated convective heat flux as the emissivity value of the shiny coating gets far from zero. On the other hand, the difference between both convective heat fluxes $\boldsymbol{q}_{C_{T E M}}$ and $\boldsymbol{q}_{\boldsymbol{F}}$ appears to be presented only for a heat flux value lower than $-1 \mathrm{~W} \cdot \mathrm{m}^{-2}$ (not presented here). Within -1 and $0 \mathrm{~W} \cdot \mathrm{m}^{-2}$, the difference between both TEM and FGT is not easy to be preceived when dividing $\boldsymbol{q}_{\boldsymbol{C}_{\boldsymbol{T} E \boldsymbol{M}}}$ by $\boldsymbol{q}_{\boldsymbol{F} \boldsymbol{F} \boldsymbol{T}}$, due to a high scattering, as expected. the radiative heat flux (see figure 11). Thus, the analysis of the estimated convective and radiative parts might lead to explain the difference between $\boldsymbol{q}_{s_{T E M}}$ and $\boldsymbol{q}_{s_{F G T}}$.

Figure 11 (b) shows that the estimated radiative heat flux resulted to be weak, where the difference encountered between $\boldsymbol{q}_{\boldsymbol{R}_{\boldsymbol{T E M}}}$ and $\boldsymbol{q}_{\boldsymbol{R}_{\boldsymbol{F} \boldsymbol{T}}}$ are somewhat undifferentiable when accounting the uncertainties. From these results, it can be shown that in a weak radiative environment, the heat flux measurement of TEM and FGT is mainly a consequence of the convective nature in the environment where the air being at a different temperature with respect to the surface, provokes the discharging or cooling of the latter, as one can fairly expect. This before leads to conclude that the difference between $\boldsymbol{q}_{s_{T E M}}$ and $\boldsymbol{q}_{\boldsymbol{s}_{F G T}}$ should be caused by the characteristics affecting the convective heat transfer.

Before going further, led us analyze if the proposed calibration methodology influences the sensitivity value of TEM, which may ultimately influence their heat flux measurement.

\subsection{Influence of the calibration method and the sensitivity value}

In $§ 2.2 .1$ the proposed calibration method was shown to be in high correspondence with the sensitivity value estimated for Captec heat flux sensors when comparing the value obtained by calibration and the value given by the manufacturer. Yet, the calibration method was performed several times for each TEM, which presented very similar values between tests, as shown in tables 2 .

Here, several questions may arise regarding the different materials in each sensor (TEM and FGT), regarding 
between $\boldsymbol{q}_{s_{T E M}}$ and $\boldsymbol{q}_{s_{F G T}}$ is entirely explained by a calibration issue, the necessary sensitivity value for TEMs

599

600

601

602

603

604

605

606

607

608

609

610

611

612

613

614

615

616

617

618

619

620

621

622

623

624

625

626

might be around two times the current value obtained by calibration, so that their heat flux measurement yields to similar values as the FGTs.

However, by equating equation 1 , it could be shown that a factor of two should be expected when comparing the TEM and FGT heat flux measurements:

$$
\frac{q_{T E M}}{q_{F G T}}=\frac{U_{T E M} / K_{T E M}}{U_{F G T} / K_{F G T}}=\frac{U_{T E M} /\left(239 \pm 3 \mu \mathrm{V} / \mathrm{W} \cdot \mathrm{m}^{-2}\right)}{U_{F G T} /\left(125 \pm 3,75 \mu \mathrm{V} / \mathrm{W} \cdot \mathrm{m}^{-2}\right)}=(0,523 \pm 0,017) \frac{U_{T E M}}{U_{F G T}} \quad .
$$

Thus, after verifying and having confidence in the proposed calibration method, it is clear that the only way for the $\boldsymbol{q}_{T E M}$ to be equal to $\boldsymbol{q}_{\boldsymbol{F} G \boldsymbol{T}}$ is that the $\boldsymbol{U}_{T E M}$ and $\boldsymbol{U}_{\boldsymbol{F} G \boldsymbol{T}}$ must present different values. In fact, $\boldsymbol{U}_{T E M}$ should present a value of about two times greater than $\boldsymbol{U}_{\boldsymbol{F G} \boldsymbol{T}}$. Also, from expression 14, it can be expected that both $\boldsymbol{U}_{T E M}$ and $\boldsymbol{U}_{\boldsymbol{F} G \boldsymbol{T}}$ should present the same value in order to encounter a factor of two when converting their electrical response into heat flux measurement.

When plotting both electrical responses, the linear regression model resulted in: $\boldsymbol{U}_{\boldsymbol{s}_{T E M}}=\mathbf{4}, \mathbf{8} \boldsymbol{U}_{\boldsymbol{s}_{F G T}}, \mathrm{R}^{2}=$ 0,9905 for the shiny ones, and $\boldsymbol{U}_{\boldsymbol{b}_{\boldsymbol{T}} \boldsymbol{M}}=\mathbf{3}, \mathbf{2 4} \boldsymbol{U}_{\boldsymbol{b}_{\boldsymbol{F} G \boldsymbol{T}}}, \mathrm{R}^{2}=0,9758$ for the black ones. The difference between the regression models obtained for the black and shiny sensors lays on the use of the exact sensitivity value of the FGT given by the manufacturer instead of the average value $125 \boldsymbol{\mu V} / \mathbf{W} \cdot \mathbf{m}^{-2}$, where $\boldsymbol{K}_{\boldsymbol{b}_{\boldsymbol{F} G T}}$ corresponds to 128 $\boldsymbol{\mu V} / \mathbf{W} \cdot \mathbf{m}^{-2}$ and $\boldsymbol{K}_{\boldsymbol{s}_{F G T}}$ corresponds to $123 \boldsymbol{\mu V} / \mathbf{W} \cdot \mathbf{m}^{-2}$.

This before shows that the ratio of the electrical responses is indeed higher than the expected, and thus, the difference encountered between $\boldsymbol{U}_{\boldsymbol{S}_{T E M}}$ and $\boldsymbol{U}_{\boldsymbol{S}_{F G T}}$ is entirely associated with the measurement of the TEMs, which turned out to be around 2,5 times too large.

At the moment, the previous analysis has shown that the electrical response of Peltier modules appears to be too large, as suggested by the analysis in $\S 3.3$, and that in this particular study, the convective part is the one affected.

Some of the causes that might be influencing the electrical response of Peltier modules can be inferred. First, a higher electrical response value should correspond to a higher temperature difference between the ceramic layer attached to the concrete surface and the one exposed to the air (in other words, a higher heat input). Since it is supposed here that both sensors TEM and FGT are exposed to the same convective and radiative conditions, e.g., airspeed, air temperature, view factors, and that the radiative part has been proven to be weak and the same between 
them, the morphology of the TEMs and the surface they are disposed might be the leading cause of the higher electrical response.

The thickness of TEMs can enhance the convective coefficient around them, which might result in an enhanced convective heat transfer causing the temperature of the surface in contact with the air to drop faster than the temperature of the surface in contact with the concrete slab (analyzing the discharging case caused by the natural ventilation scenario). If such a case is taking place, Peltier modules might be functioning as small fins (extended surface), which might explained the enhancement of the convective heat flux with respect to FGT.

The materials employed in the fabrication of Peltier modules might also allow the module to store heat as it converts the heat flux traversing it into an electric signal. The proposed calibration method has also revealed that our TEMs present a capacitive electrical response with a time response of about one minute.

On the other hand, TEMs were disposed on a concrete surface during the measurement campaigns using a high conductive thermal grease, but these modules were disposed on an aluminum surface during the calibration method. The type of surface where the sensors are installed, i.e., heavyweight, lightweight or insulating, might affect the sensors measurement depending on the effusivity characteristics of such surface. For instance, if the surface where the sensors are installed has different effusivity value, the heat absorbed by this surface would not be at the same rate the heat flux is traversing the sensor (as suggested by [12]). This might then cause the heat to be stored somewhere between the sensor or at the sensor interface with the surface on which it is disposed. This heat stored will heat up the entire module, causing its thermoelectric properties to inherit larger values. The Seebeck coefficient of semiconductor materials, $\mathrm{Bi}_{2} \mathrm{Te}_{3}$ in this case, being more susceptible to a changing in temperature than the thermal conductivity, might also provoke a higher electrical response. Also, the effect of adding the silicon paste might contribute to the heat storage, increasing the average temperature of the module.

These three last remarks concerning the TEM thickness, the energy storage in the TEM and the effusivity of the surface they are disposed, are boarded and analyzed in the following subsections.

\subsection{Influence of the heat storage and time response}

To analyze if the materials employed in the TEMs are of any influence in their heat flux measurement by the possible heat stored in them, a discretized model for the concrete slab coupled with simple heat balances for the TEM is introduced here (see figure 12). 


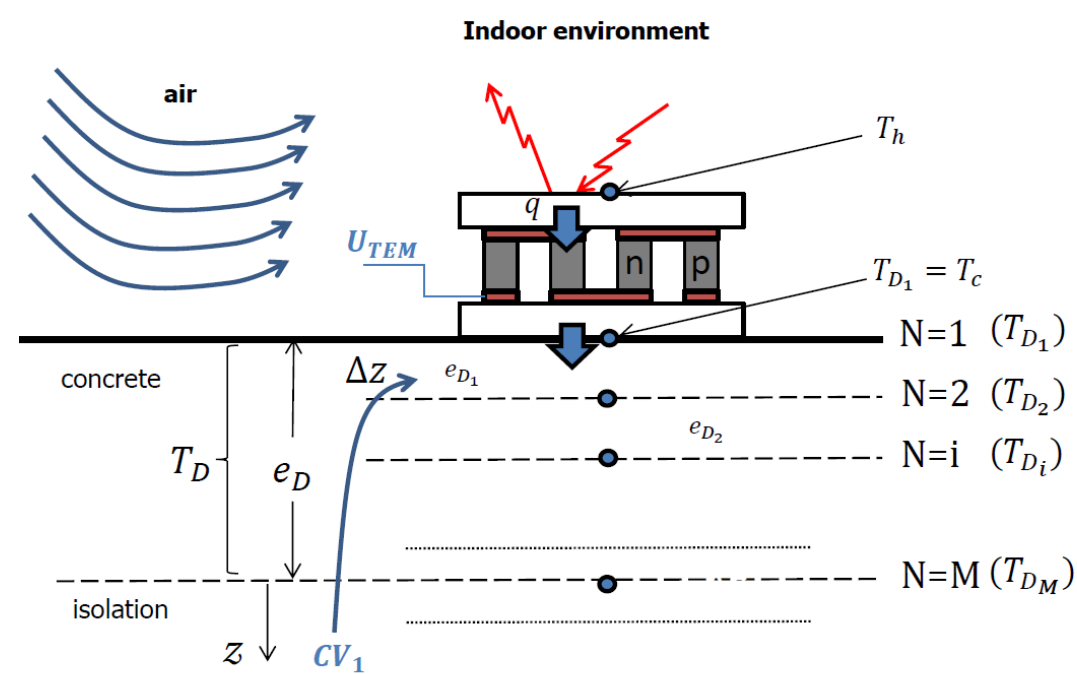

(a)

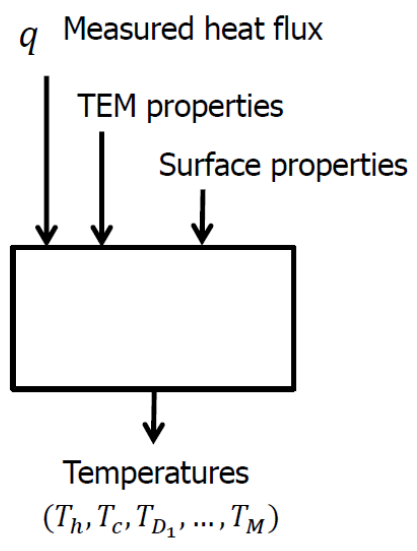

(b)
657

First, a heat balance is written for each of the ceramic layers of the TEM, as follows:

$$
\begin{aligned}
& \rho_{c e r} c_{p_{c e r}} \boldsymbol{e}_{c e r} \frac{d T_{h}}{d t}=q+\frac{\lambda_{T E M}}{e_{T E M}}\left(T_{c}-T_{h}\right) \\
& \rho_{c e r} \boldsymbol{c}_{p_{c e r}} \boldsymbol{e}_{c e r} \frac{d T_{c}}{d t}=\frac{\lambda_{T E M}}{e_{T E M}}\left(T_{h}-T_{c}\right)+\frac{T_{D_{1}-T_{c}}}{R_{c, D-T E M}}
\end{aligned}
$$

where the subscript "cer" refers to the ceramic layer. The temperatures of each ceramic layer are respectively, $\boldsymbol{T}_{\boldsymbol{h}}$ for the superior layer also referring to the "hot" layer, and $\boldsymbol{T}_{\boldsymbol{c}}$ for the inferior layer which also refers to the "cold" layer. The heat stored in the superior ceramic layer should be equal to the heat flux entering the TEM at this layer represented as $\boldsymbol{q}$, which in this case also represents the heat flux measurement, and the heat flux leaving the superior layer towards the inferior layer. The leaving heat flux is simple given by the temperature difference between the two ceramic layers times the equivalent thermal conductivity $\lambda_{T E M}$ and thickness of the sensor $\boldsymbol{e}_{T E M}$, as proposed by [5]. The heat stored in the inferior ceramic layer is then given by the heat flux leaving the superior ceramic layer and the heat flux leaving the inferior ceramic layer by conduction to the concrete slab surface. The latter is represented by the temperature difference between the inferior ceramic layer and the surface temperature of the concrete slab $\boldsymbol{T}_{\boldsymbol{D}_{\mathbf{1}}}$, divided by the thermal contact resistance between them $\boldsymbol{R}_{\boldsymbol{C}, \boldsymbol{D}-\boldsymbol{T E M}}$.

This model is attained when considering the following hypothesis:

1) The temperature of each ceramic layer is considered to be the same through the entire layer. This means that the superior ceramic layer is at the uniform temperature $\boldsymbol{T}_{\boldsymbol{h}}$. 
2) The thermoelectric properties of the sensor correspond to equivalent properties, such as the thermal conductivity $\lambda_{\text {TEM }}$, which corresponds to that of the sensor as a whole (see table 3 ). Here, this property is estimated from the impulse method electrical response determined after the calibration apparatus and fitting its response to a first order model.

3) The ceramic layers are the components materials with the most significant heat storage capacity.

Moreover, the conduction heat transfer through the concrete slab is modeled using the classic finite difference discretization approach with heat storage:

where " $\mathrm{D}$ " refers to the concrete slab, $\mathrm{N}$ to the number of node studied. Equation $15 \mathrm{~b}$ presents the boundary condition used at the superior node in contact with the inferior ceramic layer of the TEM. Finally, equation $15 \mathrm{c}$ presents the boundary condition at the bottom node " $\mathrm{M}$ " of the concrete slab is considered to be isolated, where a null heat flux is assigned.

Table 3. Values of the model parameters.

\begin{tabular}{|c|c|c|c|}
\hline Parameters & Value & Parameters & Value \\
\hline$e_{D}[\mathrm{~mm}]$ & 68 & $e_{c e r}[\mathrm{~mm}]$ & 1 \\
\hline $\mathrm{M}$ & 64 & $e_{T E M}[\mathrm{~mm}]$ & 4,8 \\
\hline$\Delta z[\mathrm{~mm}]$ & 1,06 & $\lambda_{T E M}$ & 1,6 \\
\hline$\lambda_{D}[24]$ & 1,8 & $\rho_{c e r}[5]$ & 3890 \\
\hline$\rho_{D}[24]$ & 2300 & $c_{p_{c e r}}[5]$ & 880 \\
\hline$c_{p_{D}}[24]$ & 1000 & $R_{c, D-T E M}$ & $1 \times 10^{-4}$ \\
\hline
\end{tabular}

Figure 13 shows the numerical results computed using the software R (library deSolve) with the Radau method (implicit Runge-Kutta), with a time step of five seconds. In this case, assuming a heat flux input $\boldsymbol{q}$ as the 

measurement given by the black FGT $\boldsymbol{q}_{\boldsymbol{b}_{F G T}}$. These results show that the heat storage within the TEM can be considered as no significant with respect to the heat stored in the concrete slab (see figure 13 (a)): 2,5 J for each ceramic layer. The latter is drawn from the closeness between $\boldsymbol{T}_{\boldsymbol{h}}, \boldsymbol{T}_{\boldsymbol{c}}$, and $\boldsymbol{T}_{\boldsymbol{D}_{\mathbf{1}}}$ (superposed with $\boldsymbol{T}_{\boldsymbol{c}}$ ). Although a difference in the heat flux given by the three terms on the right-hand side of equation 12 can be observed in figure 13 (b), still it can be considered as no significant since the relative error lays below 5\%.

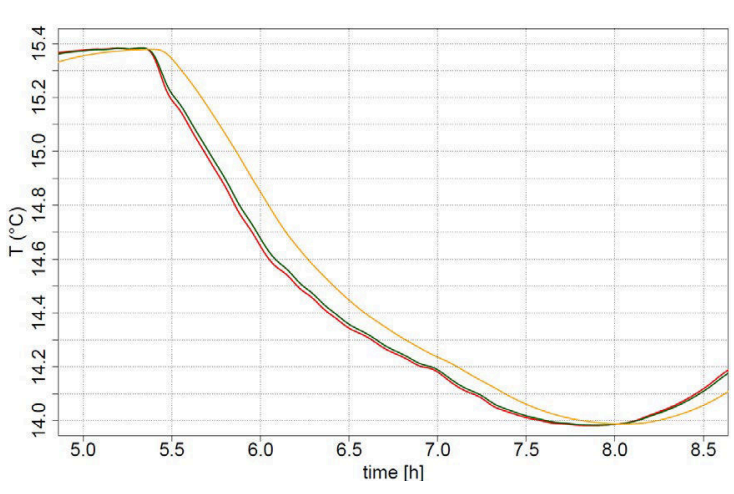

(a)

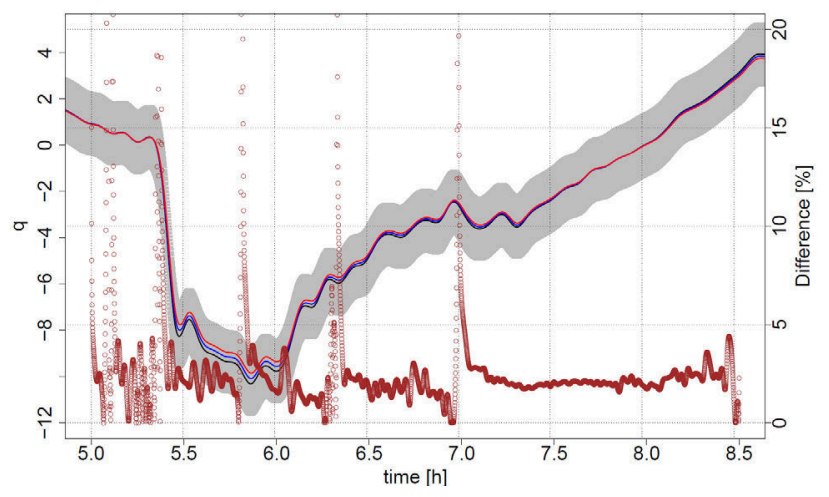

(b)

Figure 13. Numerical results when the input $\boldsymbol{q}$ is $\boldsymbol{q}_{\boldsymbol{b}_{\boldsymbol{F} G \boldsymbol{T}}}$. (a) Temperatures: $\boldsymbol{T}_{\boldsymbol{h}}$ (red), $\boldsymbol{T}_{\boldsymbol{c}}$ (dark red), $\boldsymbol{T}_{\boldsymbol{D}_{\mathbf{1}}}$ (green), and $\boldsymbol{T}_{\boldsymbol{D}_{M}}$ (orange). (b) Heat flux: $\boldsymbol{q}_{\boldsymbol{b}_{\boldsymbol{F}} \boldsymbol{T}}$ (black), between $\boldsymbol{T}_{\boldsymbol{h}}$ and $\boldsymbol{T}_{\boldsymbol{c}}$ (blue), between $\boldsymbol{T}_{\boldsymbol{c}}$ and $\boldsymbol{T}_{\boldsymbol{D}_{\mathbf{1}}}$ (red), and relative error between black and blue.

\subsection{Influence of the thickness difference}

To analyze the influence of the thickness, both TEM and FGT are considered as extended surfaces (fins) disposed over the concrete slab. Within the formulation of the heat conduction differential equation for the case of a uniform cross section fin, is the geometrical factor $\boldsymbol{f}_{\boldsymbol{g}}$ which groups the convective heat transfer coefficient with no fin $\boldsymbol{h}_{\boldsymbol{C}}$, the perimeter of the fin, its thermal conductivity and its cross sectional area: $\boldsymbol{f}_{g}=\mathbf{2} \sqrt{\boldsymbol{h}_{C} / \lambda \boldsymbol{e}}$.

When considering that the conduction heat transfer between the concrete slab and the sensor is equal to the convective heat transfer at the surface of the sensor (the tip of the fin), the analytical solution of the fin equation yields [25]:

$$
q=\frac{1}{S} \sqrt{h_{C} P \lambda S} \frac{\operatorname{senh}\left(f_{g} e\right)+\frac{h_{C}}{f_{g} \lambda} \cosh \left(f_{g} e\right)}{\cosh \left(f_{g} e\right)+\frac{h_{C}}{f_{g} \lambda} \operatorname{senh}\left(f_{g} e\right)}\left[T_{s}-T_{i a_{s}}\right] \quad\left[\mathrm{W} \cdot \mathbf{m}^{-2}\right]
$$

where the coefficient $\boldsymbol{h}_{C}$ is enhanced by the factor: $\frac{1}{S} \sqrt{h_{C} P \lambda S}\left[\operatorname{senh}\left(f_{g} e\right)+\frac{h_{C}}{f_{g^{\lambda}}} \cosh \left(f_{g} e\right)\right] /\left[\cosh \left(f_{g} e\right)+\frac{h_{C}}{f_{g^{\lambda}}} \operatorname{senh}\left(f_{g} e\right)\right]$. 

the TEM and FGT can be determined. Table 4 shows the results at different $\boldsymbol{h}_{\boldsymbol{C}}$ values. The thermal conductivity of FGT employed here is $55,6 \mathrm{~W} \cdot \mathrm{m}^{-1} \cdot \mathrm{K}^{-1}$, as computed from the value presented in [20] and the respective geometrical parameters.

Table 4. Geometrical factors for TEM and FGT at different $h_{C}$ values.

\begin{tabular}{|c|c|c|c|c|}
\hline $\boldsymbol{h}_{\boldsymbol{C}}$ & $\boldsymbol{f}_{\boldsymbol{g}_{\text {TEM }}}$ & $\boldsymbol{f}_{\boldsymbol{g}_{\boldsymbol{F} G \boldsymbol{T}}}$ & $\boldsymbol{f}_{\boldsymbol{g}_{\text {TEM }}} / \boldsymbol{f}_{\boldsymbol{g}_{\boldsymbol{F G T}}}$ & $\boldsymbol{q}_{\boldsymbol{T E M}} / \boldsymbol{q}_{\boldsymbol{F G T}}$ \\
\hline 2 & 32,27 & 16,96 & 1,90 & 3,41 \\
\hline 3 & 39,53 & 20,77 & $"$ & 3,44 \\
\hline 4 & 45,64 & 23,99 & $"$ & 3,44 \\
\hline 5 & 51,03 & 26,82 & $"$ & 3,55 \\
\hline 6 & 55,90 & 29,38 & $"$ & 3,39 \\
\hline
\end{tabular}

From table 4 it can be observed that the simple morphology of the TEM increases the heat transfer rate by convection with respect to the FGT, despite the value of the convective heat transfer coefficient (range of values chosen according to the working convective heat flux and temperatures results). In this table, second column from right to left, it can be seen that a factor of two should indeed be expected, merely by the difference between the geometrical parameters and the materials of the sensor.

Moreover, under the hypothesis of convective heat transfer only at the surface of the sensor (the end of the fin), which seems fairly straightforward since the length of the fin is smaller in this case with respect to the cross sectional area, a ratio of about 3,4 should rather be expected between the convective parts of both sensors. The latter seems to fall within the ratio encountered in $\$ 3.3 .2$, when accounting for the uncertainties. Thus, at the moment, all the analysis presented here before bring us to conclude that the leading cause of the difference between the measurements of TEM and FGT, might indeed be due to not only their geometrical properties but also to their thermal properties. This last remark bring us to propose a correction to the measurement of TEM when use as in the "measurement device."

The following section is dedicated to test the proposed "measurement device" and decoupling model for estimating the convective and radiative parts in a strong heat flux environment. 


\section{Application of the measurement device and the decoupling model: Case of strong radiative heat flux on} an external wall in controlled conditions

The experiments were designed to characterize the thermal properties of a multilayer wall, placing the "measurement device" on its front and rear faces, under laboratory conditions (see figure 16). In this study, apart from the installation of the measurement device, a Captec heat flux sensor without coating $\left(5 \times 5 \mathrm{~cm}^{2}\right)$ was installed (see figure 16 (b)), merely as a reference. The emissivity of the latter is known. The wall structure is composed of the following layers from the front face to the rear face: Mortar $(1 \mathrm{~cm})$, concrete $(20 \mathrm{~cm})$, insulation $(4 \mathrm{~cm})$, and plaster $(1,25 \mathrm{~cm})$.

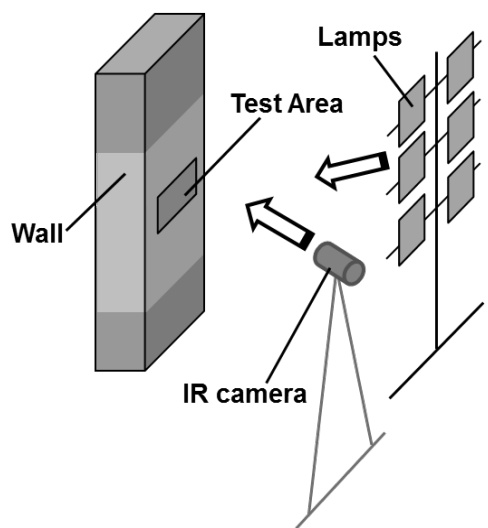

(a)

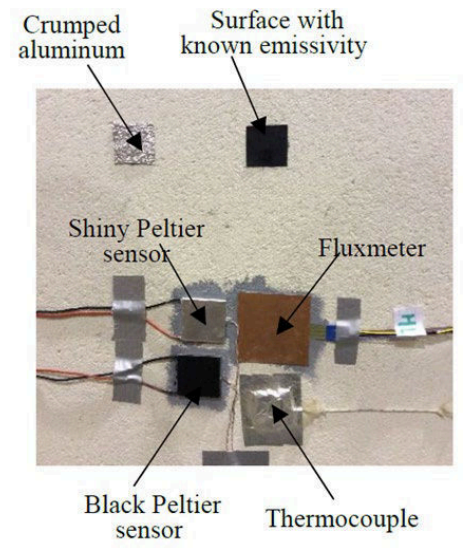

(b)

Figure 16. (a) Schematic of the experimental setup, and (b) the "measurement device" installed on the front face of the wall.

The experimental protocol followed in this study consisted of heating the test area using a set of six halogen lamps, with available radiation intensity from 0 to $1380 \mathrm{~W} \cdot \mathrm{m}^{-2}$, by inducing a square-wave signal of 24 hours period. This corresponds to a 12 hours heating or charge period followed by a 12 hours cooling or no charge period, where the lamps were turned off. The majority of the emitted energy from the lamps (up to 85\%) lies in the infrared and near-infrared regions of the spectrum, with 15 - 20\% falling into the visible (400 to $700 \mathrm{~nm}$ ), and less than $1 \%$ in the ultraviolet wavelengths (below $400 \mathrm{~nm}$ ).

The resulting temperatures of each sensor in the test area are presented in figure 17 (a). Note here that the wall surface temperature is measured by a thermocouple pasted at the wall surface using thermal silicon grease covered with a shiny coating (see figure 16 (b)). 
As expected, the black TEM presents the highest temperature value during the charge period and, despite the closeness of all temperatures during the no charge period, the black TEM also presents the lowest temperature value, due to radiative properties of its surface coating. For the shiny TEM and the FGT, it can be observed that despite their low emissivity, both heat flux meters heat up during the charge period, indicating that their absorptivity values may not be the same as their emissivity values, otherwise they might not heat up when the heating source has LWL nature only, according to Kirchhoff's law of radiation. As the nature of the lamps implemented here are of the halogen type (put wavelength range), the absorptivity values of the coatings were chosen from the literature, being $0,97,0,15$ for the black and shiny coatings respectively, and 0,65 for the wall surface $[26,27]$.

777

778

779

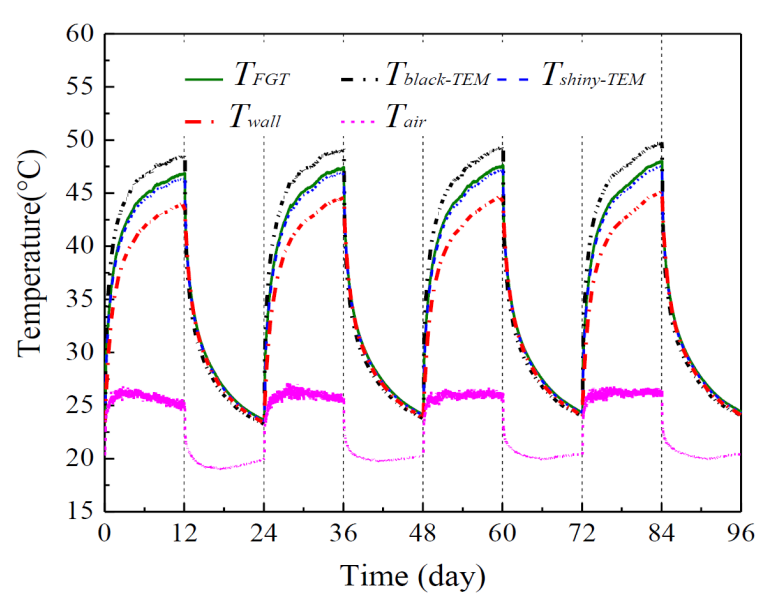

(a)

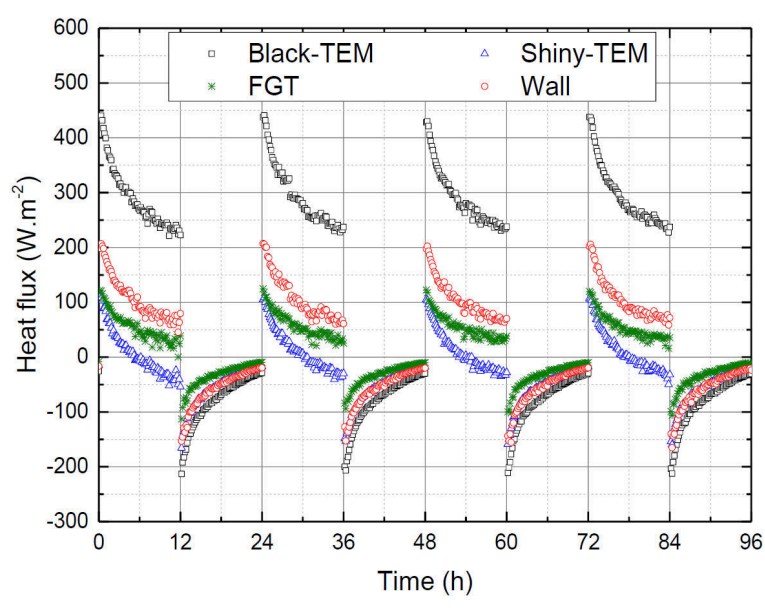

(b)

Figure 17. For four consecutive charge and discharge periods: (a) Temperature results (b) Heat flux.

$$
\text { The heat flux measurements from the black and shiny TEM, and from the FGT, are presented in figure } 17 \text { (b) }
$$
for the four charge-discharge periods, along with the absorbed heat flux by the wall $q_{\text {wall }}$ computed using equations 9 and 10. As expected during the charge period, the heat flux from the black TEM presents the higher values. The heat flux measurements from the shiny TEM and FGT are affected by the radiative properties of their coating surfaces as explained before. Figure 17 (b) clearly shows that, for the discharge periods, the absorbed heat flux can be well estimated by only using a shiny TEM, despite the large values of the convective heat flux encountered. Not as so for the charge period.

The decreasing behavior of the heat flux measurements of each heat flux meter can be explained by looking closely to the convective and radiative parts of the absorbed heat flux in the first charge-discharge period presented in figure 18 (a). During the charge period $(0-12 \mathrm{~h})$, for the convective component, the negative values indicates 


\section{Conclusions}

\section{2} behavior.

that the test area is hotter than the surrounding air, which is fairly expected since the air temperature is always lower (see figure 17 (a)). This statement is also verified by the temperature difference in figure 18 (a).

Moreover, the decreasing behavior of the radiative component, presented also in figure 18 (a), might indicate that the test area is also cool down by radiation to the surrounding surfaces. During the discharge period (12 - 24 h), as the wall and sensors seek thermal equilibrium, the heat released decreases over time reaching a heat flux value close to zero. Note here that the insulated properties of the wall first layer may also help to explain this

Figure 18 (b) shows the resulting convective heat transfer coefficient using equation 11 computed for the TEM and for the FGT, during the first charge-discharge period. In this figure the ratio of both coefficients is presented using blue asterisks with its axis on the right-hand side. Clearly a difference between both coefficients is observed, having a ratio value (around two). Moreover, the convective heat transfer coefficient was also calculated using a natural convection correlation for vertical plates [28] (small red triangles), also presented in figure 18. The latter proves once again that the FGT heat flux meter estimates well enough this convective coefficient, as expected.

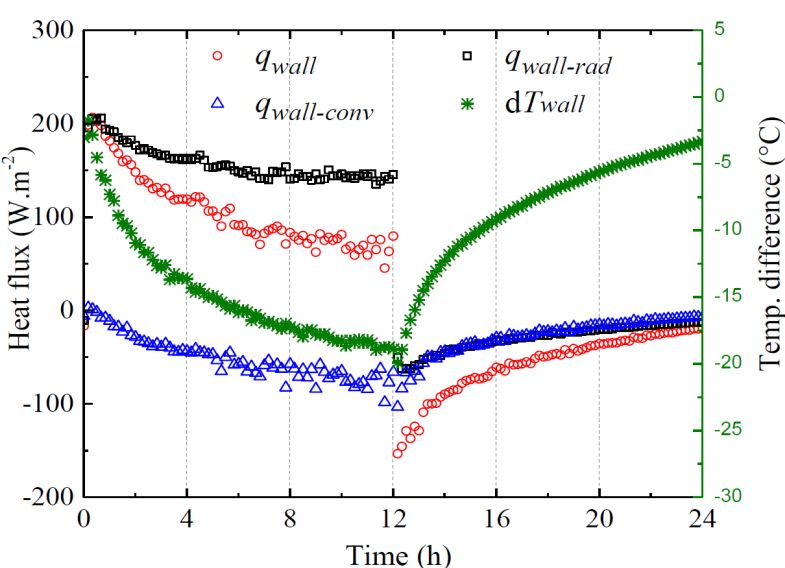

(a)

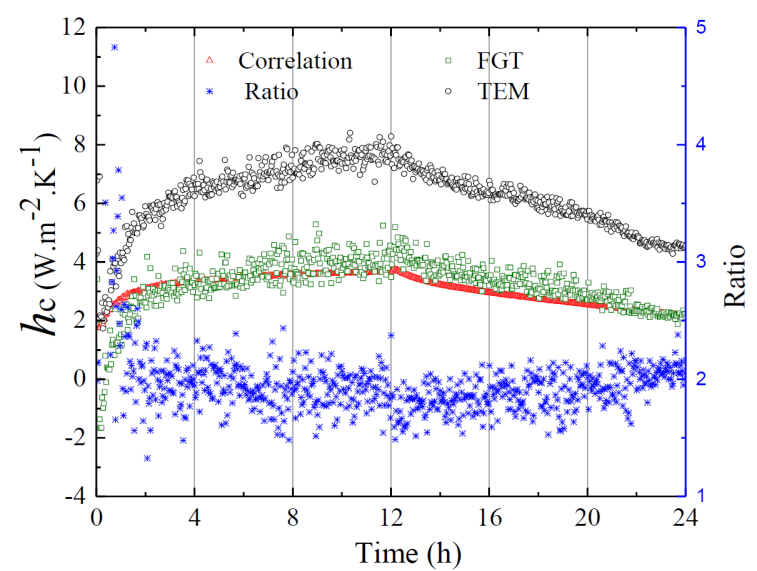

(b)

Figure 18. For the first charge-discharge period: (a) Convective heat transfer coefficient, and (b) Absorbed heat flux and the convective and radiative parts.

An experimental investigation aiming to propose the use of Peltier modules as an alternative to conventional heat flux sensors for the estimation of the convective and radiative parts, was conducted in environments presenting weak and strong convective and radiative heat fluxes. The heat flux measurement from Peltier modules (TEM) 
and conventional heat flux sensor (FGT) are compared and analyzed. Here, commercial heat flux sensors Captec ${ }^{\circledR}$ were used as conventional heat flux sensors, since as reported in the literature, their performance in the heat flux measurement has been proven to largely acceptable.

The comparison was first made in the weak heat flux environment, which consisted of a full-scale naturally ventilated positive energy house prototype, named Sumbiosi, located in Southwest France. For this, a "measurement device" consisting of a couple of black and shiny Peltier modules and three thermocouples, along with a simple model for decoupling the convective and radiative parts, are proposed here.

When estimating the convective part separately using the measurements from TEM and FGT, a difference between both measurements appears repeatedly for both cases of weak and strong heat fluxes. Three plausible causes for this difference were investigated in order to give a verified explanation: The influence of the calibration methodology implemented to find the sensitivity $\boldsymbol{K}$ of TEM, the morphology of TEM such as the thickness, and the heat storage regarding the materials employed in the TEM. the geometrical and thermal properties of the sensors. The latter was encountered when treating the sensors as extended surfaces, which showed that the difference in the measurements is expected to be encountered despite the value of the convective heat transfer coefficient.

832

\section{Nomenclature}

\section{Latin letters}

$\begin{array}{ll}q & \text { Heat flux } \\ S & \text { Surface area } \\ G & \text { Total incident radiation heat flux } \\ h_{C} & \text { Convective heat transfer coefficient } \\ K & \text { Sensitivity value } \\ N & \text { Number of thermoelectric couples } \\ U & \text { Electrical response } \\ e & \text { Thickness } \\ a & \text { Seebeck coefficient } \\ G F & \text { Geometrical factor for TEM } \\ f_{g} & \text { Geometrical factor for fins } \\ R e & \text { Electrical resistance } \\ r & \text { Electrical resistivity } \\ T & \text { Temperature } \\ c_{p} & \text { Specific heat capacity } \\ V & \text { Tension applied } \\ I & \text { Electrical current } \\ E & \text { Emitted radiation heat flux }\end{array}$

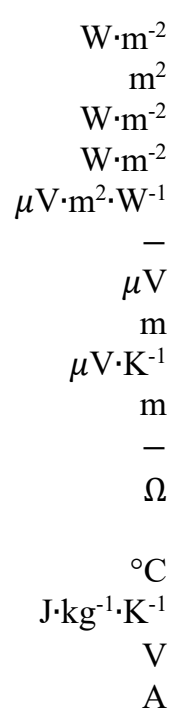

\section{Greek letters}

$\begin{array}{ll}\lambda & \text { Thermal conductivity } \\ \rho & \text { Density } \\ \delta & \text { Uncertainty }\end{array}$


$\varepsilon \quad$ Thermal emissivity

$\alpha \quad$ Thermal absorptivity

$\Delta \quad$ Refers to difference

$\sigma \quad$ Stefan-Boltzmann constant

$\mathrm{W} \cdot \mathrm{m}^{-2} \cdot \mathrm{K}^{-4}$

\section{Subscripts and superscripts}

eq Equivalent

element Semiconductor elements

$i \quad$ Surface studied

C Refers to convective

$R \quad$ Refers to radiative

$S \quad$ Shiny coating

$b \quad$ Black coating

air Refers to air

surr Refers to surroundings

ref Refers to reflected

FGT Refers to conventional heat flux sensor

1. Wu, T. et al. Thermal characteristics in situ monitoring of detached house wall constituted by raw clay. European Journal of Environmental and Civil Engineering - Taylor \& Francis, vol. 14-5, pp. 653-667, 2010. Doi: 10.1080/19648189.2010.9693252.

2. Lassue, S. et al. Mesures fluxmètriques et notion d'impédance thermique appliquées à la caractérisation d'une paroi de bâtiment soumise à des sollicitations naturelles. Materials and Structures, vol. 29-4, pp. 219-225, 1996. Doi: 10.1007/BF02485943.

3. Cherif, Y. et al. Superficial heat transfer by forced convection and radiation in a horizontal channel. International Journal of Thermal Sciences, vol. 48-9, pp. 1696-1706, 2009. Doi: 10.1016/j.ijthermalsci.2009.01.017.

4. Sommier, A. et al. Characterization of sponge cake baking in an instrumented pilot oven. International Journal of Food Studies, vol. 1, pp. 144-158, 2012. Doi: 10.7455/ijfs/1.2.2012.a5.

5. Leephakpreeda, T. Applications of thermoelectric modules on heat flow detection. ISA Transactions, vol. 51-2, pp. 345-350, 2012. Doi: 10.1016/j.isatra.2011.11.003.

6. Yang, Y. Innovative non-destructive methodology for energy diagnosis of building envelope. $\mathrm{Ph}$. D. thesis at University of Bordeaux, 2017.

7. Chen Austin, M. Couplage entre ventilation naturelle et stockage-déstockage d'énergie sensible en bâtiment : approche expérimentale et modélisation. Ph.D. thesis at University of Bordeaux, 2018.

8. Thureau, P. Fluxmètres thermiques. Techniques de l'ingénieur Mesure des grandeurs thermophysiques, base documentaire : TIB544DUO - r2900, 1996. url: https://www.techniques-ingenieur.fr\#.

9. D.M. Rowe. CRC Handbook of Thermoelectrics. CRC Press, 1995. ISBN: 9780849301469. p. 621, 678679.

10. Jangonda, C. et al. Review of Various Application of Thermoelectric Module. International journal of innovative research in science, engineering and technology, vol. 5-3, 2016. Doi: 10.15680/IJIRSET.2016.0503123.

11. Vultaggio, C. Les méthodes de la théorie du signal appliquées à l'analyse des transferts thermiques sur la surface d'une paroi opaque en régime variable. Ph.D. thesis at University of Lille Flandres Artois, 1987.

12. Herrin, P. Conception et caractérisation de capteurs de flux radiatif et convectif: application aux mesures " in situ ». Ph.D. thesis at University of Lille Flandres Artois, 1988.

13. Lassue, S. Analyse des échanges radiatifs et convectifs à la surface d'une paroi opaque : application à la commande optimale du système habitat. Ph.D. thesis at University of Lille Flandres Artois, 1989.

14. ElHarzli, M. Analyse des échanges radiatifs et convectifs à la surface d'une paroi opaque : application à la commande optimale du système habitat. Ph.D. thesis at University of Sciences and Technologies of Lille, 1993. 
15. Azerou, B. Conception, réalisation et mise en ouvre de fluxmètre thermiques passif et dynamique à base de couches minces. Ph.D. thesis at University of Nantes, 2013.

16. Douiri, I. Instrumentation dun four pilote pour la cuisson de genoise. Ph.D. thesis at Ecole Nationale Superieure des Industries Agricoles et Alimentaires, 2007.

17. Legloanec, E. Non-intrusive thermal measurement methods adapted to painted cave walls. QIRT 2014. Doi: 10.21611/qirt.2014.192.

18. Lassue, S. et al. A Convective and Radiative Flux Sensor for Designing Thermal Comfort Controllers. Indoor Environment, vol. 1-5, pp. 293-299, 1992. Doi: 10.1177/1420326X9200100507.

19. Lassue, S. et al. Contribution to the experimental study of natural convection by heat flux measurement and anemometry using thermoelectric effects. Experimental Heat Transfer, Fluid Mechanics and Thermodynamics, pp. 831-838, 1993. Doi: 10.1016/B978-0-444-81619-1.50101-5.

20. Vogt Wu, T. Formalisme des impedances thermiques généralisées. Application à la caractérisation thermique de parois de bâtiments. Ph.D. thesis at University of Artois, 2011.

21. Oter-Duthoit, L. Application des méthodes de la théorie des systèmes à la simulation de l'évolution des flux thermiques sur les faces d'entrée et de sortie d'une parois multicouche. Ph.D. thesis at University of Sciences and Technologies of Lille, 1985.

22. Oiry, H. Etude thermique àpprofondie d'un fluxmètre à gradient tangentiel. Ph.D. thesis at University of Nantes, 1985.

23. Kline, S. J. and McClintock, F. A. Describing uncertainties in single-sample experiments. Mechanical Engineering, pp. 3-8, 1953.

24. Abadie, M. et al. Energétique des bâtiments et simulation thermique. Paris: Eyrolles, 2015. ISBN: 9782-212-14275-4.

25. Incropera, F. and DeWitt, D. Fundamentos de Transferencias de Calor. Pearson, $4^{\text {ta }}$ edición. ISBN: 97017-0170-4.

26. Abad, B. et al. Non-contact methods for thermal properties measurement. Renew. Sustain. Energy Rev., vol. 76, pp. 1348-1370, 2017.

27. Naveros, I. et al. Analysis of capabilities and limitations of the regression method based in averages, applied to the estimation of the U value of building component tested in Mediterranean weather. Energy Building, vol. 55, pp. 854-872, 2012.

28. Churchill, S.W. and Chu, H.H. Correlating equations for laminar and turbulent free convection from a vertical plate. International journal of heat and mass transfer, vol. 18, p.1323, 1975. 